NBER WORKING PAPER SERIES

\title{
REVISING COMMITMENTS: FIELD EVIDENCE ON THE ADJUSTMENT OF PRIOR CHOICES
}

\author{
Xavier Giné \\ Jessica Goldberg \\ Dan Silverman \\ Dean Yang \\ Working Paper 18065 \\ http://www.nber.org/papers/w18065 \\ NATIONAL BUREAU OF ECONOMIC RESEARCH \\ 1050 Massachusetts Avenue \\ Cambridge, MA 02138 \\ May 2012
}

Niall Keleher, of Innovations for Poverty Action, was instrumental to the design and implementation of this study. We thank him for his important contributions to this project. We also thank James Andreoni, Stefano DellaVigna, Pascaline Dupas, Yoram Halevy, Vivian Hoffmann, Glenn Harrison, Pam Jakiela, Damon Jones, David I. Levine, Stephan Meier, Ted Miguel, Matthew Rabin, and participants in several seminars for their many helpful comments. We thank Lasse Brune, Jason Kerwin, and Prachi Jain for excellent research assistance. This research was funded by the Gender Action Plan and the Research Committee of the World Bank. The views expressed herein are those of the authors and do not necessarily reflect the views of the National Bureau of Economic Research.

NBER working papers are circulated for discussion and comment purposes. They have not been peerreviewed or been subject to the review by the NBER Board of Directors that accompanies official NBER publications.

(C) 2012 by Xavier Giné, Jessica Goldberg, Dan Silverman, and Dean Yang. All rights reserved. Short sections of text, not to exceed two paragraphs, may be quoted without explicit permission provided that full credit, including $(\odot)$ notice, is given to the source. 
Revising Commitments: Field Evidence on the Adjustment of Prior Choices

Xavier Giné, Jessica Goldberg, Dan Silverman, and Dean Yang

NBER Working Paper No. 18065

May 2012

JEL No. D81,D91,O10

\begin{abstract}
$\underline{\text { ABSTRACT }}$
The very poor in developing countries often make intertemporal choices that seem at odds with their individual self-interest. There are many possible reasons why. We investigate several of these reasons with a lab-in-the-field experiment in rural Malawi involving large stakes. We make two contributions. First, we construct a new dependent variable: revisions of prior choices regarding the allocation of future income. This allows us to directly examine intertemporal choice revision and its determinants. In particular, this dependent variable permits a novel test for the existence of self-control problems: we find that revisions of money allocations toward the present are positively associated with measures of present-bias from an earlier baseline survey, as well as the (randomly assigned) closeness in time to the first possible date of money disbursement. Second, we investigate other potential determinants of revision, aside from self-control problems. We find little evidence that revisions of money allocations toward the present are associated with spousal preferences for such revision, household shocks or the financial sophistication of respondents.
\end{abstract}

\author{
Xavier Giné \\ The World Bank \\ 1818 H Street N.W. \\ Mail Stop MC 3-307 \\ Washington, D.C. 20433 \\ xgine@worldbank.org \\ Jessica Goldberg \\ University of Maryland \\ Department of Economics \\ 3115G Tydings Hall \\ College Park, MD 20742 \\ goldberg@econ.umd.edu
}

\author{
Dan Silverman \\ Department of Economics \\ University of Michigan \\ Ann Arbor MI 48109-1220 \\ and NBER \\ dansilv@umich.edu \\ Dean Yang \\ University of Michigan \\ Gerald R. Ford School of Public Policy \\ and Department of Economics \\ 735 S. State Street, Room 3316 \\ Ann Arbor, MI 48109 \\ and NBER \\ deanyang@umich.edu
}




\section{Introduction}

Intertemporal tradeoffs are central to many economic decisions. As a result, wellbeing depends importantly on the ability to make and execute plans about choice over time. This is perhaps especially true among the poor in developing countries, whose decisions about consumption smoothing and about investment in small businesses, agricultural inputs, education, and health are often critical to their wellbeing.

Because intertemporal choices have such important consequences for the poor, there is special concern about the quality of their decisions in this domain. Many point to evidence of incomplete consumption smoothing, a lack of saving, inadequate use of inexpensive agricultural and health inputs, or the widespread rejection of fair crop insurance, and are puzzled. When it comes to intertemporal choice, it often appears as though the poor are not pursuing their own best interest, often with profound consequences.

A long tradition in development economics suggests that this appearance of suboptimal choice may often be misleading. There are many reasons why, given the incompleteness of markets and information in poor countries, it may be optimal to have consumption be unsmooth, to do little saving, or to miss opportunities to invest in high-return inputs. ${ }^{1}$ Yet, in recent years, analysts have brought renewed attention and tools of analysis to study the role played by self-control problems. This attention is motivated, in part, by the fact that self-control problems appear common in developed economies, and there is no reason to think that the very poor would be immune. The new focus on self-control is also motivated by evidence that people often fail to execute their stated plans for important intertemporal choices. For example, when we asked farmers in Malawi how much fertilizer they planned to use in the upcoming planting season, a large majority (85\%) said they planned to use some. Eight months later, when we asked them how much they actually used, half said they used less than they had planned; and most of those used less than half of what they planned. In addition, a growing literature shows substantial demand for, and consequences of, commitment devices designed to overcome problems of self-control. $^{2}$

In this paper, we investigate several potential sources of failure to pursue what appear to be individually optimal intertemporal choices. More specifically, we study the reasons why, after

\footnotetext{
1 Much of the seemingly puzzling evidence regarding intertemporal choices of the poor, and several explanations for it, are nicely summarized in Banerjee and Duflo (2011).

2 Ashraf et al (2006), Duflo, Kremer, and Robinson (2011), Dupas and Robinson (2011), Brune et al (2011).
} 
they make choices about future consumption, people often want to revise those choices. The paper makes two contributions. First, we test for the presence of self-control problems using a novel and robust method. Second, we provide a quantitative analysis of this and other motives for the adjustment of prior choices.

Applied research most often models self-control problems as the result of present-biased (hyperbolic or quasi-hyperbolic) time discounting. This modeling strategy is founded, in part, on evidence of non-constant time discounting. Several studies can be interpreted to show that time discount rates decline as tradeoffs are pushed into the temporal distance. ${ }^{3}$ In particular, many of experimental studies document "static” preference reversals: under commitment, subjects choose the larger and later of two rewards when both are distant in time, but prefer the smaller and earlier one as both rewards draw nearer to the present.

Interpreted as present-biased time discounting, these static preference reversals have many implications. Most important, when utility is time-separable, present-biased time discounting implies time-inconsistency; the choices (plans) that a person makes now about consumption at a later date are different from the choices she would make when that date arrives. Self-control problems and a demand for commitment may thus emerge. The important consequences of this time-inconsistency have been studied in many different contexts. ${ }^{4}$

While the study of self-control problems emerging from (quasi-) hyperbolic time discounting is now voluminous, gaps remain. Most relevant for this paper, there is to our knowledge no direct field evidence that static preference reversals are associated with time-inconsistency. Indeed, other than Halevy (2011), who performed a classroom-based study with approximately 150 college students, there have been no lab or field studies where the revision of previous decisions is the dependent variable of interest. Instead, prior work has either studied the static preference reversals themselves, the stability of time preferences, or the relationship between static preference reversals and the demand for commitment. ${ }^{5}$

3 See Ainslie (1992), Thaler (1991) and papers in Loewenstein and Elster (1992), for reviews of this evidence.

4 Early contributions include Phelps and Pollak (1968), Laibson (1997) and O'Donoghue and Rabin (1999). See DellaVigna (2009) and Bryan, Karlan and Nelson (2010) for recent reviews of empirical applications.

5 See Frederick et al. (2002) for a review of the literature on static preference reversals and Meier and Sprenger (2010) on the stability of time preferences. Ashraf, Karlan, and Yin (2006) find that women in the Philippines whose survey responses indicate present-bias have higher demand for a commitment savings device. Brune, Giné, Goldberg, and Yang (2011) do not find a relationship between measures of hyperbolic discounting and demand for a commitment savings device among male tobacco farmers in Malawi. Kaur, Kremer, and Mullainathan (2011) show in a field experiment that self-control problems lead workers to exert less effort than they themselves would like, and demand commitment devices to motivate themselves. 
The demand for commitment is, like time-inconsistency, a signature prediction of hyperbolic discounting models. But studies that focus on the demand for commitment may understate self-control problems. First, demand for commitment requires some sophistication on the part of respondents: individuals who are naïve about their self-control problems should not want to limit their future choices. Second, the design of commitment devices may be imperfect, further dampening observed demand (Beshears et al., 2011).

Testing the central mechanism linking static preference reversals to self-control problems a correlation between them and the revision of prior choices - is important because the static reversals allow several interpretations, only some of which lead to problems of self-control. ${ }^{6}$ Some static preference reversals may, for example, reflect predictable changes in the marginal utility of consumption. ${ }^{7}$ A consumer who made static preference reversals for this reason would not exhibit time-inconsistency. In addition, some static preference reversals may reflect inattention, confusion about tradeoffs, or responses to perceived experimenter demands. ${ }^{8}$ It is unclear whether consumers who make such choices under commitment would also tend to revise them later if the commitment is relaxed. Furthermore, even if preferences under commitment were well-described by changing time discount rates, the simple act of making a plan may importantly limit what would otherwise be important problems of self-control. ${ }^{9}$ Concerns about self-image and the importance of following through might trump the effects of changing time discount rates. In this case, again, static preference reversals under commitment would not predict time-inconsistent behavior.

A corollary of the lack of research on the relationship between static preference reversals and the revision of prior choices is that we have little experimental evidence about the relative importance of other explanations for the revision of prior choices. In this paper, we examine three additional determinants of revision. The first is social pressure: the influence of spouses,

\footnotetext{
${ }^{6}$ Halevy (2011) distinguishes between time-consistency, time-invariance, and stationarity, making clear that static preference reversals are identified with non-stationarity but need not imply time-inconsistency.

7 This observation has been made by Andersen et al. (2008), Andreoni and Sprenger (2010) and Noor (2011), who note that proper inference about time discounting requires information about the curvature of the utility function.

${ }^{8}$ The correlation between test scores, cognitive load and short-term patience in Benjamin et al. (2006) lends some support to this conjecture.

9 Academic psychology points to the important effects of making plans or setting goals on self-control and self-efficacy (Bandura, 1997). Evidence of the importance of planning is also seen in Ameriks et al. (2003). This idea is also broadly consistent with economic models of costly self-control such as Gul and Pesendorfer (2001), Ozdendoren et al. (2009), and Fudenberg and Levine (2010), in which consumers may both seek commitment and, yet, not always exhibit time-inconsistency.
} 
relatives, and others in one's social network. Especially in rural communities, individuals in developing countries are often obliged to share their income with relatives and friends, ${ }^{10}$ and such pressure may be an important factor behind the revision of previous decisions and an apparent inability to pursue privately optimal choices. ${ }^{11}$ Second, shocks such as deaths, illness, or unexpected changes in income could change the optimal time path of consumption, making revisions desirable. Third, individuals could make mistakes in their original decisions, and seek to revise them upon realizing the error.

A better understanding of the relative importance of these four potential determinants of revision - present-biased preferences, social pressure, shocks, and mistakes - has important policy implications. Most directly, this understanding is crucial for the design and welfare analysis of commitment devices. If social pressure affects revision, then this may reveal an additional benefit of commitment devices: preventing future plans from being subverted or undone by others who may have different preferences. ${ }^{12}$ If shocks drive revision, policy-makers must confront the important cost that commitment devices can impose by reducing individuals’ abilities to deal with the unexpected (cf. Amador et al., 2006). If mistakes are an important source of revisions, then this may also mean that commitment devices can be harmful, as mistakes cannot later be corrected. Thus, if social pressure, shocks, or mistakes turn out to be important determinants of revisions, then commitment devices could be designed either to shield resources from one's social network, while maintaining access for oneself, or to allow access in the case of emergency or verifiable error.

To investigate these issues, we implemented a lab-in-the-field experiment that takes revision of a previous decision as the key dependent variable of interest. Our sample consists of several hundred wife-husband pairs in rural Malawi, who were interviewed separately and who made independent decisions. We elicited intertemporal choices by adapting Andreoni and Sprenger’s (2011) convex time budget (CTB) method, with large real stakes (roughly a month’s wages). Individual subjects chose an allocation of money to be disbursed at two points, 61 and

\footnotetext{
${ }^{10}$ See, e.g., Platteau, 2000; Maranz, 2001; Anderson and Baland 2002; Ligon, Thomas, and Worall, 2002; Hoff and Sen, 2006; Baland, Guirkinger and Mali, 2011; Jakiela and Ozier, 2011.

11 Ashraf (2009) and Schaner (2011) experimentally document strategic behavior between spouses related to financial decisions.

12 The effect of social pressure would be different from those of social learning. With the latter, commitment may prevent optimal adjustment to the arrival of new information from others.
} 
91 days, in the future. ${ }^{13}$ A subset of these subjects were revisited some time prior to $t=61$ and given the opportunity to revise the allocation between $t=61$ and $t=91$. The extent of this revision is our dependent variable. We examine correlates of this revision decision corresponding to each of the four potential determinants of revision outlined above. Surveys at the baseline and revision stages measured household wealth, income, and expenditures as well as the participants’ expectations for each of these variables.

In addition, we implemented a complementary test of hyperbolic discounting models in our experimental context: average revisions toward sooner should be larger the shorter the time lag between the revision decision and the first disbursement date $(\mathrm{t}=61)$. We randomized the number of days prior to $t=61$ when each experimental subject had to make the revision decision. ${ }^{14}$

We find that initial allocations usually adhere to the law of demand; individuals allocated more income to later periods when offered higher rates of return to waiting. We interpret this to indicate that experimental subjects mostly understood the choices they were making and made them in a way that economic theory has some hope of explaining. We also find that "static" preference reversals are frequent, but only slightly more likely to be “present”-biased (as opposed to "future"-biased). This finding largely contrasts other studies using the multiple price list (MPL) method, but is consistent with Andreoni and Sprenger's (2011) findings that UC San Diego students exhibit no present-bias on average.

Turning to revision behavior, we find that revisions are common, often substantial in size, and shift money both sooner and later. We find support for “present”-biased preferences as a driver of revisions: subjects shift more money toward sooner when: (1) their initial allocations are "present"-biased, and (2) the time lag to disbursement is shorter (when the revision decision is made six or fewer days prior to day $t=61$ ). In contrast, we find no evidence that social pressure importantly affects revision decisions. We estimate, with considerable precision, that respondents’ revisions are not much higher when one’s spouse's sooner allocations are larger than one's own, or when the subject lives with many other relatives in the village. Similarly, we find little evidence that shocks or financial sophistication (a proxy for mistakes in initial allocations) strongly predict revisions, though here the standard errors on our estimates are sufficiently large that we cannot reject a null hypothesis of large effects.

\footnotetext{
13 These dates fell within Malawi's annual hungry season, just prior to the annual harvest, when food stocks are at their lowest and consumption smoothing is a paramount concern.

14 The revisit date was drawn randomly from a uniform distribution of 2-16 days prior to day $\mathrm{t}=61$.
} 
The rest of the paper is organized as follows. The next section presents details of the experimental design, the sample of participants and the setting of the experiment. Section 3.1 presents the results of stage one of the experiment and choices under commitment. Section 3.2 discusses the results of stage two and choices upon revisiting. In section 4 we discuss some prior studies of intertemporal choice and explain our contribution to the literature. Section 5 offers some conclusions and suggests avenues for work.

\section{The Experiment}

The experiment proceeded in two stages and was conducted with approximately 1,100 households (2,200 individuals) in rural Malawi. The timeline of the experiment is presented in Figure 3. In stage one, we adapted the methods of Andreoni and Sprenger (2011) to elicit choices under commitment. The head of household and his spouse each made several independent choices about the allocation of a substantial amount of money over time. Each choice was an allocation of an endowment between two periods, one "sooner" and one "later." Participants were paid a return on the part of the endowment that was saved for later. Each participant made 10 allocation choices: one choice for each of five different rates of return in two different time frames, one in the near future (the "near" time frame) and one in the more distant future (the "far" time frame). Choices regarding the near time frame allocated money between tomorrow and 30 days from tomorrow. Choices regarding the far period allocated money between 60 days and 90 days from tomorrow. All choices were incentivized. Participants knew that either the household head or his spouse would be randomly selected to have one of his or her choices implemented, also selected at random. The stakes were high. On average, the total allocation amounted to approximately a month's wages for a worker in rural Malawi. Stage one was implemented in the middle of the rainy season, a time of planting and cultivating, not harvesting. At this time of year, cash income is very low, and will be low for the next few months, after stage two is completed.

Stage two of the experiment applied only to those households whose implemented choice concerned the more distant future. At a randomly selected day in the two weeks prior to the arrival of the first disbursement of their money in the far period (61 days after the first stage was implemented), the household was unexpectedly revisited. At that visit, the household member whose choice was implemented was reminded of the decision he or she made at stage one, 45-60 
days earlier under commitment. That previous choice was made clear and salient. Then, facing the same rate of return, the participant was allowed to revise the original allocation decision. That decision (revised or unrevised) was then implemented with certainty. Surveys at both stages measured household wealth, income, and expenditures as well as the participants' expectations for each of these variables.

We now turn to a description of the setting and its advantages for the experiment, followed by a more detailed description of the two stages of the experiment.

\subsection{The Setting}

As a setting for experimental study of intertemporal choice, rural Malawi has a number of advantages. Most important, financial markets are thin there, especially during the rainy season when the entire experiment was conducted. As a consequence, participants lack effective methods for smoothing the large amounts of new consumption made possible by the experiment.

The farmers in our study have virtually no cash during the rainy season; and borrowing substantial cash in rural Malawi during the rainy season is not merely expensive, it often appears impossible. Similarly, short-term saving is difficult due to limited banking institutions, and familial or social demands for what appears like excess cash. ${ }^{15,16}$ This lack of borrowing and saving opportunities is important because it sharply reduces the smoothing opportunities that confound efforts to elicit time preferences in developed economies. In economies with thick financial markets and low transaction costs, answers to the questions asked in typical time-preference experiments should, in theory, bracket only the market rates of return that participants face, and reveal very little about their "true” preferences regarding consumption (Fuchs, 1982). ${ }^{17}$ To the extent that rural Malawi in the rainy season approximates autarchy,

15 Data from a 2008 nationally representative survey in Malawi indicates that only 26 percent of respondents use a formal financial product, and around 60 percent had never heard of a savings account (FinScope, 2008).

${ }_{16}$ Longer-run saving instruments are more common, typically in the form of agricultural inputs, such as livestock.

17 To illustrate, suppose that outside of the lab a participant can borrow or save at market rate $r$ and faces no financial transaction costs. A typical experiment asks the participant to choose between $\$ x$ sooner or $\$\left(1+r_{e}\right) x$ later, where $r_{e}$ denotes the rate of return implied by the later option. The participant may view this as a choice between Option $A, \$ x$ sooner and access to the interest rate $r$, and Option $B, \$\left(1+r_{e}\right) x$ later and access to the interest rate $r$. If $r_{e}>r$, then the set of allocations of consumption between sooner and later is strictly larger under option $B$ than under option $A$. Thus, for any monotonic preferences, option $B$ is preferred. Analogously, if $r_{e}<r$, then $A$ is preferred for any monotonic preferences. 
smoothing is made much more difficult. This is especially true for the participants in our experiment because the stakes are so large and involve cash rather than grain or other consumption goods that they likely have in store. It is thus difficult for respondents to draw down stores in anticipation of the arrival of the large influx of cash. In sum, studying intertemporal allocations in rural Malawi provides data that, in principle, is closer to the theoretical concepts of interest: preferences over the time-allocation of consumption.

Another advantage of this particular group of rural Malawians is that they had been involved in a previous field experiment and were familiar with the team of enumerators and experimenters. ${ }^{18}$ This may have contributed to the low (less than 10 percent) attrition rate between phase one and two, about 45 to 60 days later.

Rural Malawi also has disadvantages as a location for experiments on time preference. First, participants have low levels of formal education and may therefore find the somewhat abstract experiment difficult to grasp, or view it differently than we would expect. Participants make a living from seasonal crops, so they are uncommonly familiar with the problem of smoothing consumption over time. But, because we asked them to make choices in an unfamiliar context, it is natural to worry about participants' ability to understand the experiment as an economic decision. For this reason, our analysis takes special care to evaluate the consistency of participants' choices with a basic feature of rational economic decision-making: the law of demand. ${ }^{19}$ We interpret the degree of consistency with the law of demand as a measure of participants' understanding of the trade-offs involved in their decisions.

In addition, we avoided some asymmetries in the way people received the experimental payments between the "near" and "far" time frames by delivering two vouchers, one for the "sooner" period (either the day after the visit or 60 days from then) and one for the "later" period (30 days from the day of the visit or 90 days from then, depending on the time frame) redeemable for cash from an office set up for this purpose in a nearby town. Put differently, if payments had been made in cash during the experiment, then allocations to the "sooner" period in the "near" time frame could have been favored (relative to allocations in the "far" time frame) if participants mistrusted the experimenters or if the relatively poor infrastructure in the area resulted in substantial transaction costs to redeeming the "later" period voucher. However,

18 The previous commitment savings experiment is described in Brune, Giné, Goldberg, and Yang (2011).

19 See Choi et al. (2007, 2011). 
because payments were deliberately made available no sooner than one day after the choices were made, we cannot study preferences regarding consumption in the present; and we cannot observe the consequences of changes in time discounting that occur as just as intertemporal tradeoffs are made strictly later than the present. To the extent that changes in time discounting are largest then, we would expect any relationships between choice under commitment and revision behavior to be attenuated. ${ }^{20}$

\subsection{The Sample}

Participants in the experiment were drawn in January and February 2010 from a population of rural households in central Malawi who grow tobacco as their main cash crop. In the 2008-2009 growing season, these farmers were under contract with (the subsidiaries of) two large tobacco companies. The companies organized the farmers into clubs that range in size from three to 43 members. To facilitate timely revisiting, we limited our sample to those farmers located near a main trading center in the town of Mponela (population 13,670), and who lived in six traditional authorities (TAs) in the Dowa and Ntchisi districts. To allow relatively easy access to participants and to facilitate their access to the cash disbursements, we included all farmers in these TAs that were 2008-09 members of clubs in which the median club member lives 25 kilometers or less from the disbursement office, located in Mponela. ${ }^{21}$ Finally, to facilitate study of interactions within the household, we further restricted our sample to farmers who were part of a married couple.

These sample restrictions leave us with 1,268 targeted farmer households. A total of 1,071 households (84.4\%) and 2,142 respondents were successfully interviewed at baseline. A subset of 661 respondents (randomly selected from the full set of baseline respondents in a manner described in section 2.4 below) make up the stage two sample to be revisited.

Table 1 provides some summary statistics of baseline survey responses. In the full sample (Panel A), the median respondent is 46 years old, has four years of formal education, lives in a village with 120 inhabitants, including two relatives other than his or her spouse. There is,

\footnotetext{
20 The method of delaying early payments by one day (known as "front end delay" payment) has been used in the literature by Pender (1996), Andersen, Harrison, Lau and Rutstrom (2008) and Bauer, Chytilova and Morduch (2010), among others.

21 Scheduling for the stage one visit was done by stratifying scheduling across agricultural zones. Within a zone, the order in which clubs were visited was randomly assigned. Scheduling was done on a club-by-club basis in order to facilitate field work since members of the same club often live within the same village or in neighboring villages.
} 
however, considerable variation in these demographic variables despite being drawn from the same population of tobacco farmers in central Malawi.

The summary statistics reveal important features of participants' wealth and income. When compared to typical households from low-income countries, the households in the sample are poor. In the central Malawi region we study, however, tobacco farmers have similar poverty and income levels to those of non-tobacco-producing households. ${ }^{22}$ At the time of the baseline survey, the median participant's household has zero balances in a formal bank, and the 90th percentile of the bank balance distribution is just 700 Malawi Kwacha (henceforth MK), or approximately US $\$ 4.67 .^{23}$ The survey also inventoried the household's non-cash assets including livestock and agricultural and household durables; and participants were asked to estimate how much they could earn by selling those assets. When we include the self-reported value of these assets, we find that the median household held just 4,446 MK of wealth and the 90th percentile held 25,800 MK.

Since the baseline was conducted during the rainy season, several months would elapse before the cash crop or primary staple (maize) would be ready to be harvested in mid-April or early May. The summary statistics bear this out. The median household expects virtually no income between the interview date and April 2010.

\subsection{Stage One: Choices Under Commitment}

Figure 3 presents the timeline of the experiment. Upon initiating the interview, the household head and his spouse were physically separated. Then, after a few basic questions regarding demographics, each made five independent choices regarding the allocation of 2000MK between tomorrow (“sooner”) and 30 days from tomorrow ("later”).

More precisely, each participant was presented with a small bowl containing 20 beans (tokens) and two empty dishes, dish $A$ and dish $B$. One token allocated to dish $A$ corresponded to 100MK tomorrow. One token allocated to dish $B$ corresponded to100MK $*(1+r) 30$ days from tomorrow, where $r$ is the rate of return for waiting 30 days. The rate of return took on five different values: $0.10,0.25,0.50,0.75$, and 1.00 . The rates of return rose, in order, with each of

\footnotetext{
22 Based on authors' calculations from the 2004 Malawi Integrated Household Survey (IHS), individuals in tobacco farming rural households in central Malawi live on PPP\$1.48/day on average, while the average for central Malawian rural households overall is PPP\$1.51/day.

${ }^{23}$ At the time of the study, the relevant exchange rate was roughly 150 MK per US dollar.
} 
the five allocation choices; and participants knew that would happen. For each rate of return, the participant set out an allocation of tokens to the dishes, the tokens were translated into Malawi kwacha, and the total was written above each dish on a whiteboard. Having seen the allocation in kwacha, the participant had the opportunity to adjust the allocation. This process was repeated until the participant indicated that she was ready to move on to the next allocation choice.

After completing the first five choices, the participant answered a series of other questions from the baseline survey. (See Appendix A for details.) Then, using the same elicitation method with cup, beans, and dishes, the participant again made five independent choices regarding 2000MK, while facing different rates of return for waiting. This time, each of the five choices concerned the allocation of money between 60 and 90 days from tomorrow (the "far" time frame). Figure 1 presents a schematic of the method used to elicit intertemporal choices under commitment.

The interruption between the five choices in the near period and the five choices in the far period was intentional. We sought to avoid having participants choose the same allocations in both time frames simply for the sake of being (or appearing) consistent. In addition, the order in which the time preference sections of the questionnaire were administered was, in fact, randomly assigned between households within tobacco clubs. With 50 percent probability, a participant was first asked to make decisions about the allocation of money in the "near" time frame, between tomorrow and 30 days from tomorrow. Otherwise, a participant was first asked to make decisions about allocations in the "far" time frame, between 60 and 90 days from tomorrow. Controlling for any effects of these alternative orders does not affect the results, and the order in which time frames were presented does not predict choices.

Before making their choices, each participant knew that one member of the couple would be randomly chosen to have one of his or her choices implemented (also randomly selected). The randomization was performed on site, by rolling dice. Implementation took the form of a voucher, redeemable at the disbursement office in Mponela. The voucher indicated the allocation (some amount at time $t$ and another amount at time $t+30)$ and was issued to the member of the couple who was randomly chosen. Identity of the recipient was established with a name and a fingerprint placed on the voucher. ${ }^{24}$

${ }^{24}$ Giné, Goldberg, and Yang (forthcoming) find that fingerprinting is an effective means of economic identification 


\section{$2.4 \quad$ Stage Two: Revisiting the Decision}

In stage one of the experiment, one of each household's 20 decisions (10 of the husband's and 10 of the wife's decisions) was randomly selected to be implemented. If the selected decision concerned an allocation in the near time frame, between tomorrow and 30 days from tomorrow, which happened with probability one-third by design, then the experimental intervention was finished for that household. The chosen individual in the household redeemed its allocation and was not interviewed again. Stage two of the experiment was only carried out with those households whose randomly selected decision concerned an allocation in the far time frame, between 60 and 90 days from tomorrow.

In stage two, this group of households was unexpectedly revisited. The targeted date for revisiting was randomly selected from the interval between 16 and 2 days prior to the first possible disbursement of funds in the far period. Thus, these households were targeted to be revisited between 45 and 59 days from their baseline interview. Revisits occurred even if the household chose an allocation involving no disbursement of funds at 61 days from their interview. ${ }^{25}$ Revisit dates occurred in March and April 2010.

At the revisit, the household head and his spouse were physically separated and the survey of wealth, income and expenditure was performed again. After the interview was conducted, the participant whose choice had been selected to be implemented was again presented with a cup containing 20 tokens. This time, however, four dishes were placed in front of the participant: dishes $A, B, A^{\prime}$ and $B^{\prime}$. Dishes $A$ and $B$ contained a total of 20 tokens allocated to reflect the participant's original decision at baseline. Dishes $A^{\prime}$ and $B^{\prime}$ were empty. The participant was told that the first set of dishes showed his or her baseline choice; an allocation between what was effectively one to 16 days from the revisit and 30 days from then. This information was verified with the voucher that was issued at baseline. The participant was also reminded of the rate of

\footnotetext{
in the context of lending in rural Malawi.

${ }^{25}$ In all that follows, we focus on the randomly-assigned targeted lag (in days) to first disbursement, since it is exogenous to farmer actions. We made the first attempt to revisit each respondent on the date implied by the randomly-assigned target lag. In some cases, the actual lag was smaller (closer to the disbursement date) than the targeted lag, because some farmers could not immediately be located and had to be found thereafter. The actual lag is, as expected, highly correlated with the target lag; the correlation coefficient is $0.99 .84 .9 \%$ of respondents were revisited with exactly the targeted lag, and 97.4\% were revisited no more than two days after their target date. The maximum difference in the sample between target lag and actual lag is six days. Actual lags spanned the range of 16 to one days prior to first disbursement.
} 
return for waiting that applied at baseline, and the tokens on dishes $A$ and $B$ were translated into kwacha using whiteboards.

The participant was then asked to allocate the 20 tokens in the cup between the empty dishes $A^{\prime}$ and $B^{\prime}$, where the same rate of return for waiting applied. The allocation to the second set of dishes was again translated into kwacha and the participant was asked if he or she wanted to adjust the allocation. This process was repeated until the participant indicated he or she was finished. Then a new set of vouchers were issued (regardless of whether the allocation was revised), and the interview was concluded. Figure 2 presents a schematic of this revising procedure.

The revising procedure is intended to measure the presence and magnitude of revisions of individuals' previous choices. We therefore made the original allocation decision salient and unambiguous. The procedure is also designed to balance the consequences of implicit experimenter demands or connotations of a right answer. The participant must actively choose an allocation by placing tokens in the dishes, and the status quo is thus discouraged. The mere fact that we revisited the household and allowed a revision might also imply that some change is appropriate (otherwise, why would we allow it?). However, because the original allocation is set out just next to new allocation, there should be no difficulty replicating the original allocation and perhaps some mild, but implicit encouragement to do so. Especially given the rural setting, and the difficulty of double blind protocols, we cannot hope to eliminate the consequences of implicit experimenter demands. Instead we designed the experiment to limit the biases they might generate.

The conceptual key to the revising procedure is that participants recall, with perfect accuracy, the allocation they chose at baseline. We then seek to quantify the extent to which they deviate from that allocation, and learn more about why they deviate. In this way, the experiment is importantly different from an experiment designed to evaluate the stability of preferences regarding a delay of fixed length of time (Harrison, Lau and Rutstrom, 2005). If that were the goal, we would not have reminded participants of their original choice and we would have repeated the elicitation method after a fixed length of time had elapsed. Instead, we make the original choice unambiguous and randomly choose the delay from a two week interval.

The two randomizations carried out in stage two -- the implemented choice, and the revisit date -- generated exogenous variation in two independent variables that will be of interest in the 
regression analysis. First, the implemented choice generated exogenous variation in the interest rate that applied to the revision decision. The second is the targeted revisit date itself. Consistent with the fact that these two variables were randomly assigned, both the implemented interest rate and targeted days to first disbursement are for the most part uncorrelated with key baseline respondent and household characteristics. ${ }^{26}$

\section{Results}

In this section we first describe the results from stage one of the experiment, and we define key variables from the choices made under commitment used in the analysis of revision behavior in stage two.

\subsection{Stage One: Choices Under Commitment}

\subsubsection{Theoretical Framework}

To guide interpretation and fix ideas, consider first a canonical, deterministic problem of choice over time. In that problem the decision-maker solves

$$
\begin{array}{cc} 
& \max _{\mathbf{c}=\left(c_{1}, c_{2}, \ldots, c_{T}\right) \in \mathrm{R}_{+}^{T}} U(\mathbf{c}) \\
\text { s.t. } & k_{t+1}=\left(k_{t}-c_{t}\right)(1+r) \\
& k_{0}=\bar{k}, k_{T} \geq 0 .
\end{array}
$$

The consumer thus chooses a bundle of consumption, $\mathbf{c}$, the elements of which are indexed by time, to maximize the utility function $U$. The choice of $\mathbf{c}$ is restricted to a feasible set defined by the intertemporal budget constraints (1) and the boundary conditions (2), where $r$ is the interest rate, and $k_{t}$ is the stock of savings at time $t$. The usual assumptions are (i) Monotonicity ( $U$ is increasing in each element of $\mathbf{c}$ ) which implies that other things equal more is preferred to less, (ii) Diminishing marginal utility ( $U$ is concave inc) and so smoother

\footnotetext{
${ }^{26}$ Appendix Table 1 presents results of regressions of a number of key baseline variables on an indicator for days to first disbursement (targeted) being less than or equal to six (Panel A) and on the implemented interest rate (Panel B). (The specification of the target lag as an indicator is chosen to be consistent with the specification in the main regressions of Table 6, and is discussed further below.) In each panel, the coefficient on the randomized right-hand-side variable is not statistically significantly different from zero for 10 out of the 12 dependent variables. Having two out of 12 coefficients turn up significant is close to what would have occurred by chance, and all these variables (and others) will be included as controls in the regression analyses below. Results are similar when these regressions are run with alternative specifications for the randomized right-hand-side variables, such as linear days to first disbursement or dummies for each discrete implemented interest rate.
} 
allocations tend to be preferred and (iii) Impatience, that is, other things equal, consumption is preferred sooner rather than later. Given a feasible set, choices about the allocation of consumption over time are driven by all three of these usual assumptions.

We will interpret participants’ choices under commitment in stage one, as solving a special version of the canonical model, where $U$ is time separable. Abstracting from the discrete nature of the choice set, we will interpret stage one decisions as solving, for each rate of return $r$ :

$$
\begin{aligned}
& \max _{\left(c_{t}, c_{t+30}\right) \in \mathrm{R}_{+}^{2}} u_{t}\left(c_{t}\right)+\delta_{t} u_{t+30}\left(c_{t+30}\right) \\
& \text { s.t. } c_{t}+\frac{c_{t+30}}{1+r}=2000 M K
\end{aligned}
$$

Note that flow utilities and the time discount factors need not be time-invariant. Time-varying flow utilities allow for the possibility of predictable changes in the marginal utility of consumption. Time-varying time discount factors allow for the possibility that, as has often been observed, time discount rates depend on the intertemporal distance to the trade-off. While this framework is deterministic, our analysis makes use of survey evidence regarding the real-life uncertainty that participants face.

Notice that, absent additional assumptions, the specification in the problem defined above is not identified. It is trivial to show that for any collection $\left(u_{t}, u_{t+30}, \delta_{t}\right)$ that reconcile the choice data, there is another collection $\left(u_{t}^{\prime}, u_{t+30}^{\prime}, \delta_{t}^{\prime}\right)$ also consistent with the data.

\subsubsection{Adherence to the Law of Demand (Monotonicity)}

We have just argued that the preference parameters of the problem above are not identified. However, additive separability and montonicity of the flow utilities make a strong prediction. If participants solve the problem above, then the allocation to the later period, measured in kwacha, should increase with the rate of return to waiting $r$. To see why this is true, it is useful to think of $\left(\frac{1}{1+r}\right)$ as the price of consumption later in terms of consumption sooner. When $r$ goes up, the price of later consumption goes down. The result is an income effect creating incentives to increase consumption in both periods, and a substitution effect that is positive for consumption in the later period. Thus both income and substitution effects lead to increased consumption (kwacha) in the later period. ${ }^{27}$

\footnotetext{
27 The allocation to the earlier period can go up or down depending on whether the income or substitution effect
} 
As a first step, we evaluate the extent to which participants' choices are consistent with this basic prediction of rational choice with time-separable, monotonic utilities. We view this as a logical pre-condition for interpreting the choices under commitment as revealing preferences in the context of a canonical model. To the extent that choices are inconsistent with the law of demand, it suggests either that participants did not understand the trade-offs involved in their decisions very well, or that the canonical model is poorly suited for interpreting and making predictions about their behavior.

Since each participant made ten intertemporal allocation decisions, we evaluate adherence with the law of demand by dividing these decisions into pairs, where each element of the pair is a choice regarding an allocation of kwacha over the same two dates. The first element of the pair is the allocation chosen when facing rate of return $r$. The other element is the allocation chosen when facing rate of return $r^{\prime}$, the next lowest rate of return. For each participant there are eight such pairs, four for each of the two time frames. ${ }^{28}$ A total of 2,142 participants completed the baseline survey and stage one of the experiment. The data thus contain 17,136 pairs of decisions where $r$ increases by one increment; of these, 13,859 (81\%) were such that the allocation to the later period increased with $r$. Thus, approximately $81 \%$ of pairs were consistent with this basic prediction of rational choice with monotonic, time-separable utility. In addition, the typical deviation from consistency is fairly modest in size. The median violation could be made consistent with a reallocation of less than two tokens.

It is instructive to compare this percentage of consistent pairs with one generated from a simulation where the same sample of participants make choices purely at random (see Appendix B for details). Results from the simulation suggest that the percentage of consistent pairs is significantly lower at 57\%. We therefore interpret the results to indicate that, on average, participants understood the trade-offs they were facing and that the time-separable version of the canonical model is reasonable for describing average behavior.

The average rates of adherence with the law of demand do, however, mask some important heterogeneity. Table 2 presents the distribution of participants by the number of times they increased their later allocation with a single increase in the rate of return $r$. Recall, there are eight such pairs for each participant and thus the number of times a participant can be consistent

dominates.

${ }^{28}$ Note that a subject who did not change his or her allocation of tokens within a pair would still appear consistent with this prediction; the allocation to the later period would increase with $r$. 
by this measure ranges from zero to eight. Column 1 of Table 2 shows that, measured in this way, $31.3 \%$ of participants are always consistent and $75.7 \%$ are consistent at least three quarters of the time. At the other end of the spectrum, $10.2 \%$ of the sample violated this form of consistency at least half the time. We will return to investigate the correlates of this heterogeneity below.

For comparison purposes, column 2 of Table 2 reports the simulated distribution of consistent choices if participants were to choose consumption randomly. According to column 2, virtually nobody is always consistent under random choice and only $16.9 \%$ are consistent at least three quarters of the time.

\subsubsection{Intertemporal Trade-offs Under Commitment}

With greater confidence that most participants understood the trade-offs involved in their choices, and that the canonical model is a reasonable description of their behavior, we further examine decisions under commitment. Table 3 presents some summary statistics of these choices, displayed separately by time frame -- tomorrow vs. 30 days from tomorrow (near) and 60 and 90 days from tomorrow (far). More precisely, Table 3 describes the distribution of allocations to the later period, in kwacha.

Several features of this distribution are worth noting. First, participants typically reveal a willingness to balance allocations between the two periods that is consistent with the canonical model described in Section 3.1.1. For example, when facing a rate of return to waiting of 50\%, the median choice allocates $1,950 \mathrm{MK}$ to later and, thus, $700 \mathrm{MK}$ to sooner. A minority of allocations (12\% to 23\%) are corner solutions. This willingness to locate at an interior allocation is consistent with participants not having, or not realizing they have, meaningful smoothing opportunities. The tendency toward interior solutions also points, in the absence of very high rates of time discounting, to the importance of diminishing marginal utilities of income.

A second important feature of this distribution is the heterogeneity in preferences that it reveals. In the nearer time frame, the tenth percentile allocates just 750MK (6 of 20 tokens) to the later period when the rate of return is $25 \%$. The 90th percentile allocates all of its endowment to the later period. This heterogeneity is to some extent predictable with observable characteristics of the participants. Table 4 shows the results of a regression of the difference between the natural $\log$ of the allocation to sooner and later on the rate of return $r$ and 
observable characteristics of the participants. These results provide some evidence that, conditional on the rate of return, those with more wealth at baseline allocate more to later, as do those with more relatives who live in the village. There is also some weak evidence that those who scored higher on the word recall test and the financial literacy questions allocate more of their endowment to later, but that those who score higher on the Raven's test allocate less of their endowment to later. Measured in this way, we find no evidence that education has a significant relationship with patience in this domain.

The estimates in Table 4 have the advantage of being easily interpreted in terms of a simple economic model of intertemporal choice. If we adopt the canonical model in Section 3.1.1 and assume stationary, isoelastic utilities $\left(u(c)=\frac{c^{1-\rho}}{1-\rho}\right)$, then the coefficient on $r$ is an estimate of $\frac{1}{\rho}$. The disadvantage of this specification is that it excludes corner allocations, where the log of consumption at one time or the other is undefined. Analysis of a levels specification gives qualitatively similar results (available upon request) with more evidence of a positive correlation between word recall and the willingness to postpone consumption.

\subsubsection{Static Preference Reversals}

A third important feature of the distribution choices displayed in Table 3 is its apparent stability across time frame. Comparing the top and bottom halves of Table 3 shows that the distribution of allocations to later is not dramatically altered by the change in time frame. For example, the mean allocation to later when facing a $25 \%$ rate of return is $1,536 \mathrm{MK}$ when the trade-off is between tomorrow and 30 days from tomorrow. The analogous number is $1,565 \mathrm{MK}$ when the trade-off is pushed 60 days into the future. This average stability is, however, somewhat misleading. It both overstates the stability of individual choices across time frames and masks heterogeneity in individual tendencies to shift allocations forward or back, depending on frame.

Each participant makes five pairs of decisions where each element of a pair differs only in the time frame. Of the total of 10,710 such pairs, just 2,927 (27\%) are identical and just 4,895 (46\%) differ by a token or less. Thus, in more than half of all such pairs the elements are substantially different from each other. There is a relatively modest tendency for these static preference reversals to be “present”-biased. Of the 5,815 pairs that differ by strictly more than a token, 3,061 (53\%) allocate more to the sooner date when the trade-off is between 1 and 30 days. 
The remaining $47 \%$ of these preference reversals allocate more to the later date when the trade-off is between 1 and 30 days from tomorrow. ${ }^{29}$ Consistent with the "magnitude" effect, static preference reversals are more common at lower rates of return for waiting. ${ }^{30}$ When the rate of return for waiting is $10 \%$, just $41 \%$ of pairs differ by a token or less.

In this way, the results of stage one of the experiment indicate that static preference reversals are common, but that "present"-biased reversals are only somewhat more common than those in which participants appear less patient as intertemporal trade-offs are pushed into the temporal distance. There is evidence, however, that these static reversals are not merely noise. Among those participants who exhibit static reversals, a substantial fraction (18\%) is "present"-biased in at least four of five decisions. Simulations of purely random choice indicate that the percentage of individuals with at least four of five "present"-biased pairs would be less than $8 \%$. In addition, the tendency to be consistent or "present"-biased is somewhat predictable with observable characteristics of the participants.

Table 5 presents the results of regressions that relate a participant's tendency to be consistent or "present"-biased to observable characteristics. In each column the dependent variable is either the fraction of pairs of decisions in which the participant was dynamically consistent or the fraction the participant was present-biased. The first column of Table 5 indicates that males and those with greater maize stores tend to be more dynamically consistent. Column 3 of Table 5 indicates that these variables have similar relationships (with opposite signs) with fraction present-biased, though these relationships are not statistically significant.

Columns 2 and 4 reveal an important relationship. There is a strong association between adherence to the law of demand as described in section 3.1.2 and static preference reversals as measured here. Those with a higher share of pairs of choices that adhere to the law of demand (as in Table 2) are much more likely to make dynamically consistent choices. ${ }^{31}$ This link suggests that the tendency to exhibit static preference reversals may be attributable, in part, to a

\footnotetext{
${ }^{29}$ When choices are generated at random, only $4.77 \%$ are equal and $13.85 \%$ differ by one token or less. As expected, preference reversals are equally split between present and future biased (43\% each).

30 The magnitude effect refers to the finding that individuals appear more present-oriented when the stakes are smaller. See, e.g., Thaler, (1981) Loewenstein (1987) and Benzion et al. (1989).

${ }^{31}$ Note there is no mechanical reason why these two measures must be linked. The first regards the response of allocations to changes in $r$, within time frame. The second regards consistency of allocations, given $r$, across time frames. For example, a subject who always violated the law of demand could be perfectly dynamically consistent, simply by replicating his non-monontonic allocations in both time frames.
} 
poor understanding of the choice environment and the trade-offs involved. We pursue this hypothesis further as we examine the revision behavior in stage two of the experiment.

\subsection{Stage Two: Undoing Commitment}

Having described some basic features of preferences under commitment, we now examine the relationship between revision behavior in stage two of the experiment, on the one hand, and preferences under commitment and other participant characteristics on the other. Our goal is to evaluate, quantitatively, the importance of time preferences relative to other motives for revision.

\subsubsection{Qualitative Features of Revision Behavior}

Because this is, to our knowledge, a first attempt to study revision behavior in a field experiment, we begin with a simple description of the choices upon revisiting. Recall that stage two of the experiment applies only to those households whose randomly selected choice was an allocation between 61 and 91 days from the baseline interview. The randomization was designed to favor (with two-thirds probability) the later time frame, so we aimed to revisit 722 respondents and present them with a revision opportunity. Of these we were successful in collecting revision choice data from 661 (91.6\%).

A first observation about revisions is that they are common. While the experiment made the original choice clear and salient, 65\% of participants (432) made some adjustment to their allocation decision. $^{32}$ It could be that implicit experimenter demands caused some participants to feel as though some change was expected of them. However, a large majority (87\%) made a reallocation involving a shift of at least two tokens, and 64\% made a reallocation involving a shift of at least 4 tokens. Figure 4 presents a histogram of changes in the participants' allocations to sooner ( $\mathrm{t}=61$ ) upon revisiting, excluding those who made no change (who represent $35 \%$ of observations), and illustrates the frequency of relatively large revisions.

A second observation about the revisions distribution is that revision decisions shift the allocation of income forward and backward in time with nearly equal frequency. Of the 432 participants who made some adjustment to their allocation decision, 52\% shifted income toward sooner and 48\% shifted income toward later. As the histogram also indicates, the adjustments that moved allocations toward later tended to be more modest in size. Of these, approximately

\footnotetext{
${ }^{32}$ When we simulate random choices, only $4.7 \%$ individuals (one in 21) would not adjust their allocation decision.
} 
$56.5 \%$ involve the shifting of at least 4 tokens, and just $15.5 \%$ involve shifting 10 tokens or more. The comparable numbers for adjustments that moved allocations toward sooner are $70.2 \%$ and $25.8 \%$.

\subsubsection{Who Revises?}

Having described some basic features of revision behavior, we move on to consider the correlates of these choices. Of primary interest is the extent to which revision behavior is related to preferences under commitment, proximity to the first disbursement of cash, and to measures of financial sophistication, shocks, and social pressure.

Table 6 presents the results of ordinary-least squares regressions relating revision behavior to variables capturing all these potential determinants as well as baseline characteristics. In each column, the dependent variable is the change to sooner allocations upon revisiting (in Malawi kwacha). In the example depicted in Figure 2, the dependent variable would take the value 200MK (as two tokens were added to the time $t$ dish, compared to the original allocation).

In the first column of the table, the right-hand side variables are restricted to baseline characteristics and the implemented interest rate. The coefficient on the implemented interest rate is negative and statistically significant at the $5 \%$ level. Respondents revise less towards sooner at higher rates of return. Coefficients on baseline characteristics indicate that males and younger individuals (those aged 56 or below) revise more towards sooner, while those in the highest education categories (primary and more than primary) revise less towards sooner. Baseline maize stores and wealth have little power to predict revisions.

In column 2, we investigate the predictions of hyperbolic time-discounting models. We take two approaches to this investigation. First we evaluate the central prediction of hyperbolic discounting models: if "present"-biased static preference reversals are due to hyperbolic discounting, then these static reversals should be correlated with "present"-biased time-inconsistency (revisions toward sooner).

In adopting this first approach, we want a non-parametric measure of an individual's tendency to make "present"-biased static preference reversals. ${ }^{33}$ A simple measure would calculate the number of times (or the fraction) out of a possible five that a respondent made a

${ }^{33}$ An alternative approach would parameterize the utility function in problem $(\mathrm{P})$ and estimate its parameters for each individual. The primary disadvantage of this method is that identification must rely on functional form assumptions. Absent such assumptions, the utility function in (P) is not identified. 
“present"-biased preference reversal. ${ }^{34}$ This would be an appropriate measure in a deterministic model of choice, where the error term of the regression captures unobserved heterogeneity in preferences. If, however, we allow for error in the implementation of "true" preferences, another measure is preferred. The preferred measure takes four of the five pairs of decisions where each element of a pair differs only in the time frame and calculates the fraction of those pairs in which the participant exhibited "present"-biased static preference reversals. ${ }^{35}$ We exclude from this measure the pair of choices associated with the implemented interest rate. Appendix Table 2 of the appendix provides analogous results where our preferred measure is replaced on the right-hand-side with the fraction of all five pairs of choices in which the respondent exhibited a "present”-biased static preference reversal.

We view the measure that excludes the pair of choices associated with the implemented interest rate as more conservative and prefer it for that reason. We take this view because simulation analyses (discussed in Appendix B) indicate that a model of choice with error introduces a mechanical positive relationship between present bias for the implemented choice and revisions toward sooner. To see why, consider a respondent that makes allocations completely at random in both the baseline and in the revisit. Now think about choices that exhibit "present"-bias. By definition, the allocation to sooner in the far time frame is lower than that for the near time frame. Under random choice then, the individual is likely to allocate more tokens to sooner upon revisiting and therefore, "present"-biased individuals are mechanically more likely to revise towards sooner. ${ }^{36}$ An analogous effect applies to future-biased static preference reversals and revisions toward later. Crucially, however, these spurious relationships do not exist when constructing the measures of bias from the non-implemented choices.

This non-parametric approach to measuring "present”-bias and revision behavior may understate the importance of hyperbolic discounting for prior choice revision if, as one would expect, "present"-bias is positively correlated with an overall reluctance to delay consumption. In this case, "present"-biased static preference reversals would be positively correlated with larger initial allocations to sooner that, by definition, leave less room for revisions toward sooner. For

\footnotetext{
34 This is, for example, the measure of present-bias in Ashraf et al. (2006).

35 To allow for respondent error, we consider it a reversal only if the allocations differ by at least two tokens. Results are quantitatively similar if we reduce the tolerance to just one token.

${ }^{36}$ We are grateful to Pascaline Dupas for suggesting this argument to us. The argument is similar to the one put forth by Becker (1962) to show that even individuals choosing consumption bundles at random would generate downward sloping aggregate demand. See the discussion in Appendix B for further details.
} 
this reason, we also condition on a non-parametric measure of patience: the total number of tokens the subject allocated to sooner, summing over the 9 baseline allocations (out of 10), excluding the implemented choice.

Our second approach to investigating the predictions of hyperbolic time discounting makes use of the random timing of revisit. In column 2 of Table 6 we include on the right-hand-side of the regression an indicator for the targeted lag to first disbursement being less than or equal to six days. ${ }^{37}$ This variable is included to test the basic prediction that if individuals have hyperbolic preferences, they will shift more towards the present the closer they are to the time of consumption. We chose an indicator of six days or less, which captures a third of the revisited sample, in order to balance concerns about power (which might argue for a specification that is linear in the targeted lag) against the prediction of a non-linear relationship between targeted lag and revision that comes from a model of hyperbolic time discounting.

The results of column 2 provide evidence consistent with hyperbolic time discounting. The coefficient on the indicator for 6 or fewer days to first disbursement is positive and statistically significant at the $5 \%$ level. ${ }^{38}$ In addition, the coefficient on fraction present biased is positive, and statistically significantly different from zero at the $10 \%$ level. As anticipated, the non-parametric measure of general impatience is negatively correlated with the size of revisions toward sooner; those who initially allocated more to sooner have less scope for revising further in that direction.

In column 3 we add to the regression variables intended to measure financial sophistication, which is likely to capture for the extent to which mistakes in initial allocations help explain revisions toward sooner. The point estimates of the coefficients on these variables typically have a negative sign, suggesting that those with greater sophistication tend to shift consumption toward later upon revision. But the standard errors on these estimates are so large that we cannot reject a null hypothesis of either large positive or large negative effects. ${ }^{39}$

In column 4 we add two variables to the regression representing shocks experienced during the time elapsed since the baseline survey. The point estimates on both death in the family and on the shortfall in expected income have the expected signs (negative shocks lead to more

\footnotetext{
37 In section 3.2.3 below we explore alternative specifications of the target lag variable.

38 This coefficient remains stable across specifications of the table, reflecting the fact that it was randomly assigned and therefore uncorrelated on average with other variables.

39 The set of financial sophistication variables are also not jointly significant at standard levels of confidence.
} 
revision toward sooner) but, again, the standard errors are so large that we cannot reject a null hypothesis of an economically large correlation with revisions toward sooner. ${ }^{40}$ Adding these measures of shocks does not much influence the coefficients on other variables.

In column 5, we add to the regression measures of social pressure. The first variable is one's spouse's allocation to sooner minus one's own, averaged across the 9 baseline allocations (out of 10), excluding the implemented choice. ${ }^{41}$ This variable should capture pressure to revise one's allocation toward sooner coming from one's spouse. ${ }^{42}$ The second variable is simply the number of relatives one reports having in the village, which should proxy for pressures to share with a wider social network. Both variables enter the regression positively, consistent with the pressure leading to less saving. However, the effects are precisely estimated to be economically small; we can reject a null hypothesis of large positive correlations with revisions toward sooner.

In column 6, we add several baseline characteristics of one's spouse to the regression (coefficients omitted for brevity). ${ }^{43}$ We include these variables to gauge the extent to which any of the results we have described so far may simply be due to the influence of omitted spousal variables, a concern particularly relevant for the coefficient on the spousal allocation variable in column 5. We see no evidence that this is the case. The coefficients on the variables of greatest interest do no much change with the inclusion of the spousal variables.

In sum, the patterns in the first 6 columns of Table 6 provide support for a model of hyperbolic discounting as an account of some respondents' behavior. Revisions toward sooner are larger when individuals make their revision decision closer to the funds disbursement date, and individuals whose allocations under commitment in the baseline survey are more “present”-biased choose to re-allocate more towards sooner when that commitment is broken upon revisiting. By contrast, we estimate quite precisely little effect of social pressure on the tendency to revise. Finally we find no evidence that variables representing financial

\footnotetext{
40 Deaths affect approximately $2 \%$ of households, and shocks to income tend to be small. Households expected and received virtually no cash income over the relevant period. More than the usual care should therefore be used in extrapolating these results to other settings in which consumers face greater risk.

${ }^{41}$ As with the present-bias ratio, we exclude the implemented choice from this calculation because our simulation analysis indicates that its inclusion leads again to a spurious positive relationship. See Appendix B for details.

42 Notice that revisions towards the spousal allocation could happen unwillingly, as the result of pressure from the spouse (Ashraf, 2009 and Schaner, 2011), or willingly, for example if the respondent forgot about a future expense at the time of the baseline allocation that was later pointed out by the spouse.

${ }^{43}$ These variables are: fraction present biased across all choices, indicators for age category, indicators for education category, word recall, Raven's score, financial literacy score, and fraction of decisions consistent with law of demand.
} 
sophistication or shocks have statistically significant or robust relationships with revision behavior. In this way, the results provide no support for the idea that mistakes in initial allocations (which should be more prevalent for those with lower financial sophistication) are important determinants of revision over this horizon.

The right-hand-side variables that are statistically significantly related to revision are also economically substantial. Table 7 presents a summary of magnitudes of these key relationships, using the coefficients from Table 6, column 6. A useful benchmark is the impact of a 50 -percentage point reduction in the rate of return to waiting 30 days, which leads to a 107.41 MK increase in revisions toward sooner. In comparison, a one-standard-deviation increase in the measure of present-bias is associated with 41.88 MK higher revisions toward sooner, making one's revision decision within six days of day $\mathrm{t}=61$ raises revisions toward sooner by 124.57 .

\subsubsection{Discussion and additional analyses}

Future bias vs. "present” bias

Our analysis has so far focused on the predictions of hyperbolic discounting models. This is natural given the laboratory evidence and well-developed theory surrounding them and other models of present-bias. Future bias is, however, also possible. Models of future bias would imply that respondents would shift allocations toward later as the intertemporal tradeoffs draw near. Column 7 of Table 6 considers this possibility and replacing the fraction present biased variable with an analogously-defined "fraction future biased" variable.

Contrary to a theory that attributes future-biased static preference reversals to non-constant time discounting, the coefficient on fraction future biased choices is actually positive; though it is relatively small and far from being statistically significantly different from zero at conventional levels. The results are very similar when we include the implemented choice in the measure of future bias (Appendix Table 2). There too we see no evidence that future-biased static preference reversals predict revisions toward later upon revisiting. One interpretation of this finding is that the future biased static preference reversals capture predictable changes in the marginal utility of income, more than some form of non-constant discounting. More generally, the future-biased preference reversals appear to be driven by mechanisms that do not induce time-inconsistency. 


\section{Alternate specifications of target lag}

In all regressions of Table 6, the variable for targeted days to first disbursement upon revisiting is specified as an indicator variable for six days or less. Here we elaborate on the justification for this specification.

First, we note that specifying the variable as a linear relationship leads to a similar result. If we replace the indicator target lag variable with a linear variable for targeted days to first disbursement in the specification of Table 6, column 6, the coefficient on the linear target lag variable is -10.09 and has a standard error of 5.34 (significant at the $5 \%$ level). ${ }^{44}$

It turns out, however, that the linear relationship just described masks the fact that the underlying relationship between the target lag and revisions is better described as a non-linear function. To see this, we again estimate the specification of Table 6, column 6, but now we specify the target lag as separate indicator variables for each of the 14 distinct values of the target lag from two to 15 days prior to first disbursement (the omitted indicator is 16 days). Rather than show a regression table, in Figure 5 we graphically present the estimated coefficients on the target lag indicators. The solid line graphs the series of point estimates, and the upper and lower dashed lines bound the upper and lower 95\% confidence intervals.

Point estimates on the indicators for days two through six are all large in magnitude, each exceeding $100 \mathrm{MK}$, and show no obvious time pattern. In contrast, nearly all the coefficients on the indicators for higher target lags are substantially smaller in magnitude and several are below or just at zero. (The exception is the coefficient on the indicator for 11 days, $151 \mathrm{MK}$. This is probably a chance occurrence, and the coefficient is not statistically different from zero at standard confidence levels.) Due to lack of power, most of the individual coefficients are not statistically significantly different from zero at conventional levels (although the coefficients on the indicators for days four and six are statistically significantly different from zero at the $10 \%$ level).

All told, the relationship appears to be best summarized by a step function with a positive effect for days two to six prior to disbursement, and zero effect thereafter.

\section{Attrition}

\footnotetext{
${ }^{44}$ All other coefficients in the regression remain essentially identical to those reported in Table 6, column 6.
} 
We attempted to revisit 722 individuals with complete baseline data. We were successful at revisiting 661 (91.6\%). This high revisit success rate helps ameliorate concerns over selection bias, but it is still important to ascertain the extent to which key right-hand-side variables are related with attrition, and to think through any resulting directions of bias.

Table 8 presents regressions of an indicator for inclusion in the sample on key right-hand-side variables. The sample is the 722 individuals we attempted to revisit, so the mean of the dependent variable is the revisit success rate, 0.916.Individuals targeted for revisit six days or less prior to first disbursement are 10.8 percentage points less likely to be included in the revisit sample. This reflects the simple fact that our survey team had less time to find individuals whose target revisit date was close to the disbursement date. ${ }^{45,46}$

An important question is whether the key results (in Table 6) on the impact of days to first disbursement on revisions could be driven entirely by selection, since both these variables are statistically significantly related to revisit success. Given the sizes of the effects in Table 6, this turns out to be implausible.

Consider the coefficient in column 6, Table 6 on the indicator for targeted days to first disbursement less than or equal to six, which is 124.57 . This variable leads to 10.8 percentage points lower inclusion in the sample. For differential selection on this variable to fully explain the coefficient in column 6, Table 6, revision towards sooner of individuals selecting out of the sample due to having days to first disbursement less than or equal to six would have to have been lower by 1,117.67 MK. ${ }^{47}$ A change in revisions of this magnitude would be extremely large,

\footnotetext{
${ }^{45}$ The closest randomized target date was two days prior to first disbursement, and the cutoff date for actual revisits was set at 1 day prior to first disbursement. Revisits on or after that date would be nonsensical, since the "sooner" disbursement could already have been made (if the respondent redeemed the voucher immediately on the disbursement date).

${ }^{46}$ In addition, individuals with higher word recall are less likely to be included in the sample. Two additional words recalled (about one and a half standard deviations) leads to a 3 percentage point lower likelihood of revisit success. Revisit success was higher for individuals who are younger who had lower baseline wealth.

${ }^{47}$ Let there be two types of individuals: type 1 , who we always successfully revisit, and type 2, who are only successfully revisted if days to first disbursement is $>6$. So when days to first disbursement is greater than six, the sample is composed of both types 1 and 2, while otherwise it is only composed of type 1 . Let $\mu_{1}$ and $\mu_{2}$ be mean revision for type 1 and 2 individuals, respectively. We observe $\mu_{1}$, and the problem is to estimate the value of $\mu_{2}$ such that there is actually no "effect" of days to first disbursement $<=6$, and all the observed effect in Table 6 is due to selection. The formula for $\mu_{2}$ is $\mu_{2}=\frac{(\alpha+\gamma)\left(\mu_{1}-\beta\right)-\alpha \mu_{1}}{\gamma}$, where $\beta$ is the coefficient on days to first disbursement less than or equal to six in the table (124.57), $\alpha$ is the revisit success rate for type 1 individuals (0.861), $\gamma$ is the reduction in the revisit success rate due to revisiting 6 or fewer days to first disbursement $(0.108)$, and $\mu_{1}$ is the mean revision for type 1 individuals (mean revision for those with days to first disbursement $<=6,150.0$ ). The formula gives $\mu_{2}=$ -967.67. So $\mu_{1}-\mu_{2}=150.0-(-967.67)=1117.67$.
} 
amounting to roughly the difference between the 10th percentile (-600 MK) to the 83rd percentile (500 MK) of the revision distribution, or about two standard deviations. It is highly unlikely that all the individuals selecting out of the sample would have had revisions this different from other individuals who were successfully revisited.

While it is very unlikely that the estimate of the impact of days to disbursement from column 6, Table 6 is due entirely to selection, selection may still lead to bias in this estimate. In Appendix Table 4 we present results of an exercise intended to bound the size of this possible bias, running regressions analogous to that of column 6, Table 6 but where observations that were previously not included due to attrition are now included, and where we make several different assumptions as to the value of the dependent variable for the newly-included observations. ${ }^{48}$ At the top of each column is our assumption regarding revision on the part of attrited observations. Across columns 1 through 7, we assume initial allocations to sooner are revised in the amounts (respectively) of 600, 400, 200, 0, -200, -400, and $-600 .{ }^{49}$ Looking across columns, the stability of coefficient estimates on particular independent variables provides a sense of the sensitivity of coefficients to a range of assumptions on how attrited individuals would have revised their allocations.

When assuming positive revisions toward sooner for the attrited observations, the coefficient on the indicator for days to first disbursement less than or equal to six becomes larger in magnitude, reflecting the fact that this variable is positively correlated with attrition. For the same reason, assuming negative revisions toward sooner for attrited observations leads the coefficient on this variable to become smaller in magnitude. The results indicate that the coefficient on the indicator for days to first disbursement less than or equal to six in Table 6 is robust to a wide range of assumptions on attriter revisions, except when attriter revision is assumed to be as much as -600: in this case the coefficient declines enough in magnitude to become statistically insignificant. We view an assumption that attriters revise as much as -600 MK vis-a-vis their initial allocations as farfetched; this change amounts to more than one standard deviation of the revision distribution.

\footnotetext{
${ }^{48}$ The only other difference vis-a-vis the regression in column 6 , Table 6 is that we exclude the shock variables "death in family" and "shortfall in expected household income" from the right-hand-side of the regression, since these were also measured upon revisit.

${ }^{49}$ We of course do not allow revisions to go beyond corners, imposing the restriction that revised allocations to sooner must stay within the $[0,2000]$ range. For example, in column 1 , where we are assuming that revised allocations are $600 \mathrm{MK}$ higher than attrited individuals' initial allocations, if an individual initially allocated 1700 MK to sooner, we only allow the revised allocation to sooner to go to $2000 \mathrm{MK}$ (not $2300 \mathrm{MK}$ ).
} 
Males vs. females

In Table 9 we explore whether estimated effects differ across males and females in the sample, estimating regressions analogous to column 6, Table 6, but where the sample is restricted to females (column 1) and males (column 2). We also present p-values of the F-test that coefficients on each presented right-hand-side variable differ across the female and male regressions.

Owing to smaller sample sizes, some coefficients do not achieve conventional statistical significance levels, such as those on fraction present-biased (for both genders) and on the days to first disbursement indicator (for females). But coefficient magnitudes are similar to those in the gender-pooled sample of column 6, Table 6.

For nearly all variables, coefficients are not statistically significantly different across the male and female samples, with a few exceptions. The coefficient on the Raven's test score is negative and statistically significantly different from zero among males, and is significantly different from the corresponding (positive) coefficient among females. In the female sample, coefficients on the schooling indicators are negative (indicating that higher schooling leads to less revision towards sooner), statistically significantly different from zero, and statistically significantly different from the corresponding coefficients in the male regression (or nearly so). The male coefficients on schooling, on the other hand, are positive, but none are statistically significantly different from zero. Another result that emerges is that the coefficient on the death in the family indicator is large and positive for females, smaller in magnitude and negative for males, and marginally statistically significantly different across the male and female regressions (p-value 0.106).

\section{Related Literature}

There is a long tradition of evaluating time preferences from observational choices over time. Hausman (1979), Lawrance (1991) and Warner and Pleeter (2001) are prominent examples. In this tradition, the analyst observes the (implicit) price consumers are willing to pay in order to move consumption forward in time. In Hausman (1979), for example, a time discount rate is inferred from the price elasticity of demand for long-run energy efficiency in household appliances. The early contributions to this literature assumed that time discount rates were 
constant with respect to time. More recently, observational data has been used to estimate potentially non-constant time-discount functions. This literature, which restricts itself to estimating quasi-hyperbolic discount functions, includes Paserman (2008), Fang and Silverman (2009) and Laibson et al. (2007). We depart from this literature by adopting experimental methods for eliciting intertemporal choices and working with non-parametric measures of patience and "present”-bias.

The experimental literature on time preference is large. Frederick et al. (2002) offer a review. More recent examples include, Andersen et al. (2008), Benhabib, et al. (2010), and Andreoni and Sprenger (2011). As noted above, we adapt to our field environment the methods that Andreoni and Sprenger (2011) developed for use in the lab. A key advantage of their design is that, with a convex choice set, it permits the relatively rapid collection of information on intertemporal choice in the face of several different rates of return. The method thus allows analysis of the consistency of choice with the law of demand as well as quantitative measures of the degree of dynamic inconsistency.

Most recently, experimental studies of time preference have been taken into the field, often in developing countries. Prominent examples include Harrison et al. (2005), Ashraf et al. (2006), and Tanaka et al. (2009). Two such field experiments are closely related to ours and thus merit special consideration. The first, Ashraf et al. (2006), asked a sample of 1,777 in the Philippines hypothetical time preference questions on a survey. Later, a subset of this sample was offered a commitment saving product. Women who exhibited present-biased preference reversals on the survey questions were, as predicted by theory, more likely to take up the commitment saving product. Our paper differs from this prior study, most importantly, by studying directly the link between incentivized intertemporal allocation decisions and revision of prior choices. We measure the extent of preference reversals, as well as the basic consistency of choice with rational economic models, and thus provide a quantitative assessment of the mechanisms behind time inconsistency and the demand for commitment. The second closely related paper, Harrison et al. (2005), elicited time preferences from 253 participants in Denmark. Of this sample, 97 were later revisited and, importantly, asked to perform the same time preference experiment again. Our experiment is distinguished from Harrison et al. (2005) by, among other things, making a participant's original choice clear and salient. In our view, both studies ask important and interesting questions. However, our goal is not to evaluate the stability of time preference, 
but rather to measure revisions of intertemporal plans and to shed light on the determinants of such revisions.

\section{Conclusion}

The consequences of making low quality intertemporal choices can be dire, especially among the poor in developing countries. Low-income farmers can go hungry for long periods if they fail to make good smoothing decisions. They can fail to rise out of extreme poverty if they miss opportunities to make high return investments. We conducted an experiment among Malawian farmers to investigate why their intertemporal choices may appear not to serve their individual self-interest. More precisely, we provide the first field evidence on the causes and correlates of decisions to revise prior intertemporal choices. The experiment allowed subjects to make an intertemporal allocation of substantial funds they would receive at two future times 30 days apart. This future 30-day period was timed to occur during a period of low income and low food stores, and thus consumption smoothing of substantial amounts of future income is very difficult. Several weeks later, prior to the first disbursal of funds, we revisited study participants and allowed them to revise their previous allocations over the same 30-day period. We examine these revisions of allocations for evidence of self-control problems as well as other potential mechanisms behind intertemporal choice revision.

We provide new evidence for the existence of self-control problems. Revisions of allocations toward the present are positively associated with measures of “present”-bias from an earlier baseline survey, as well as the (randomly assigned) closeness in time to the first possible date of money disbursement. ${ }^{50}$ These results complement existing evidence for self-control problems that are based on demand for commitment devices (e.g., Ashraf et al., 2006, and Beshears et al., 2011). In contrast to pre-existing work on demand for commitment devices, our approach has the advantage of allowing even naïve individuals (who are not aware of their self-control problems) to contribute to estimates, since naïve as well as sophisticated respondents can display revision behavior. In addition, analysis of revision behavior avoids problems of low demand that may arise if commitment devices are poorly designed.

50 This result is reminiscent of Kaur, Kremer, and Mullainathan’s (2011) finding that worker effort increases as a worker's randomly-assigned payday comes closer. 
While only a minority of our sample exhibits “present”-biased static preference reversals, the correlation between these reversals and revision of prior choices toward sooner is relatively large. In addition, with considerable statistical precision, we find no evidence that respondents' revisions tend to move in the direction of their spouses’ preferences for such revision. Similarly, though with less precision, we find no evidence that mistakes or shocks are important predictors of the decision to revise prior choices about intertemporal allocations.

These results thus suggest cautious optimism about the prospects for improving the lives of the very poor in developing countries by alleviating their problems of self-control. By providing evidence of the relative importance of time-inconsistency, the results support the view that, if we privilege an individual's preferences at moments relatively far from the present, the benefits of commitment may be substantial and the costs, in terms of reduced flexibility, may be slight. This view should be tempered, however, by two important caveats. First, our findings show that “present”-bias, as evidenced by static preference reversals, is far from ubiquitous in this population. Many of the participants in the experiment exhibited, at most, just a modest tendency to be “present”-biased. Policy design must take account of this heterogeneity; efforts to help some with their legitimate self-control problems must avoid saddling others with commitments they do not need. Second, and related, our experiment was conducted during the lean season when little income is generated. This makes ours an unlikely context for finding that income fluctuations influence revision. It is possible that income shortfalls may influence revision behavior in other parts of the Malawian agricultural year, such as in the post-harvest months. Our findings should therefore be tested for robustness using similar research designs in other time periods and contexts.

\section{Appendix A: Variable definitions}

The key dependent variable we analyze is change in sooner allocation upon revisiting $(M K)$, which is respondent's allocation to later period $(\mathrm{t}=91)$ in revisit survey minus allocation to later period $(\mathrm{t}=91)$ in baseline survey. All other variables are from either the baseline survey, the revisit survey, or from administrative (project) data.

\section{A.1 $\underline{\text { Variables collected in baseline survey }}$}

Present-biased ratio is fraction of choices where allocation to sooner in near period is more than 100MK higher than allocation to sooner in far period (comparing choices in near and far

periods for same interest rate). In all regressions this variable excludes the implemented interest 
rate from the calculation, but summary statistics are also included for all choices including the implemented interest rate.

Future-biased ratio is fraction of choices where allocation to sooner in near period is more than 100MK lower than allocation to sooner in far period (comparing choices in near and far periods for same interest rate). In regressions this variable excludes the implemented interest rate from the calculation.

Fraction of decisions consistent with law of demand is fraction (out of 8) of pairs of adjacent choices (adjacent in interest rates) where allocation to later rises in rate of return.

Spouse minus own allocation to sooner $(M K)$ is spousal allocation to the sooner period minus corresponding allocation for respondent, for all choices excluding the randomly-chosen implemented choice.

Implemented interest rate is rate of return to waiting 30 days for funds for the respondent's randomly-selected choice (out of 10 choices made).

$\mathrm{HH}$ total in bank is total value of balances in formal banks reported at baseline (in thousands of MK).

$\mathrm{HH}$ total cash is total value of cash held at home reported at baseline (in thousands of MK).

$\mathrm{HH}$ items is total value of physical household items and assets owned, reported at baseline (in thousands of MK).

HH animals is total value of livestock owned, reported at baseline (in thousands of MK).

Total $\mathrm{HH}$ wealth is sum of $\mathrm{HH}$ total in bank, $\mathrm{HH}$ total cash, $\mathrm{HH}$ items, and $\mathrm{HH}$ animals (in thousands of MK).

\section{A.2 Variables collected in revisit survey}

Indicator for death in family indicates death in respondent's own household in the time since the baseline survey (reported in revisit survey).

Shortfall in expected household income is expected household income minus actual household income, where expectation is reported in baseline and actual is reported in revisit survey. Both expectation and actual income reports refer to same period (time between baseline and revisit survey), reported in revisit survey.

\section{A.3 $\underline{\text { Variables from administrative (project) data }}$}

Days to first disbursement at revisit (targeted) is randomized target number of days prior to first far period disbursement that revisit survey is planned. Randomization assigns days from 2 to 16 in unit intervals with equal probability.

Days to first disbursement at revisit (actual) is actual number of days prior to first far period disbursement that revisit survey is carried out.

Indicator for days to first disbursement (targeted) $<=6$ equal to 1 if days to first disbursement at revisit (targeted) is less than or equal to 6 , and 0 otherwise.

\section{Appendix B: Simulations of stochastic choice}

In this section we assess the adherence of subjects’ optimizing behavior to the canonical model of Section 3.1.1 by comparing their choices to those of hypothetical subjects that choose randomly. Given that more than two thirds of individuals choose allocations that deviate at least 
once from the law of demand, and that more than $90 \%$ make at least one different allocation in the "near" compared to the "far" time frame, random choice seems a natural alternative model of behavior as it can explain both features of the data. ${ }^{51}$

The interest in random choice model is twofold. First, it can be used to alleviate the concerns raised in Section 2.1 about the low levels of literacy of the subject pool. In particular, we assess whether our results can be generated by individuals that do not understand the experimental protocols and that in the extreme, choose randomly. Second, as we explain in more detail below, we use the results from the random choice model to justify the construction of certain variables used in the analysis of Table 6.

We generate 1,000 random samples of 2,285 subjects who choose allocations with a probability of $1 / 21$. That is, all possible allocations ([2000,0], [1900, 100(1+r)], .. [0, $2000(1+r)])$ are chosen with probability $1 / 21$. To construct spousal controls, individuals are matched with their real life spouses and their (random) choices are used to generate the relevant variables. For each sample of random choices we run the specifications of columns 6 and 7 of Table 6 and for each coefficient in the regression, we report its mean and construct the 95\% confidence interval non-parametrically using the $25^{\text {th }}$ and $975^{\text {th }}$ coefficient.

Appendix Table 3 reports the results. We compare coefficients obtained using real data (odd numbered columns) to simulated or random choice data (even numbered columns). Columns 1 and 2 compute the "Fraction Present Biased" variable using all pairs, including the one associated with the implemented interest rate. The variable "Spouse minus own allocation to sooner" is also computed using all interest rate pairs. Columns 3 and 4, in contrast, exclude the pair of the implemented interest rate in both variables. All regressions include all the regressors of columns 6 and 7 of Table 6 . They are not reported since by definition they are uncorrelated with the random choices.

The results from columns 1 and 2 of Appendix Table 3 are remarkable. When all pairs are included, the coefficient on "Fraction Present Biased" using simulated data is almost three times larger than the coefficient when using the real experimental data. Both coefficients are large and significant at conventional levels, suggesting that a null that the coefficient is zero is rather uninformative.

The reason for the large coefficient using simulated data is a mechanical relationship between "present bias"- like behavior under the implemented interest rate and revisions to the sooner period. Intuitively, in the second stage of the experiment, an individual that exhibits "present bias" will, by definition, have chosen in the far time frame an allocation to sooner that is lower than that of the near time frame. Thus, even under random choice, the probability that the revised allocation to sooner is larger than the (below average) original allocation is relatively high -- hence the mechanical positive relationship between revision to sooner and "present bias". An analogous argument can be made to explain the mechanical negative relationship between revisions to sooner and "future bias".

Of course, there should be no relationship between random choices under interest rates other than the implemented one and revision behavior under the implemented interest rate. This therefore suggests the construction of the variables "Fraction Present Biased and "Spouse minus

\footnotetext{
51 Other models based on changes in expected income between the "near" and "far" time frame would only be consistent with individuals being either always or never dynamically consistent. If an individual expects a windfall between the near and far time frame, he or she would appear more patient in the far time frame under all interest rates. These models cannot explain why some individuals are dynamically consistent under some interest rates but not others.
} 
own allocation to sooner" excluding the choices under the implemented interest rate.

Indeed, the coefficient on "Fraction Present Bias" in column 4 is small and insignificant albeit with a rather large confidence interval. This small coefficient stands in contrast with that of column 3, replicating column 6 of Table 6.

Columns 5 to 8 study the relationship between future bias and revision behavior. As expected, column 6 displays the mechanical negative relationship between "Fraction Future Biased", computed using all interest rates and the change in the allocation to sooner. However, this relationship disappears in column 8 when the choices under the implemented interest rate are excluded.

\section{References}

Ainslie, G., Picoeconomics: The Strategic Interaction of Successive Motivational States Within the Person (Cambridge [England]; New York: Cambridge University Press, 1992).

Amador, Manuel, Angeletos, Marios, and Werning, Ivan (2006). "Commitment vs. Flexibility.” Econometrica 74(2), 365-396.

Ameriks, J., A. Caplin and J. Leahy (2003) Wealth Accumulation and the Propensity to Plan. Quarterly Journal of Economics, 118, pp. 1007-1047.

Andersen, Steffen, Glenn Harrison, Morten Lau and Elisabet Rustrom (2008). Eliciting Risk and Time Preferences, Econometrica 76(3), 583-618.

Andreoni, James and Charles Sprenger (2011). "Estimating Time Preferences from Convex Budgets,” working paper, UC San Diego.

Ashraf, Nava (2009), "Spousal Control and Intra-Household Decision Making: An Experimental Study in the Philippines,” American Economic Review, 99(4), 1245-1277.

Ashraf, Nava, Dean Karlan and Wesley Yin (2006). Tying Odysseus to the Mast: Evidence form a Commitment Savings Product in the Philippines, Quarterly Journal of Economics 121(2), 635-672.

Baland, J. C. Guirkinger and C. Mali (2011). "Pretending to be poor: borrowing to escape forced solidarity in credit cooperatives in Cameroon," Economic Development and Cultural Change, Vol. 60, No. 1, pp. 1-16.

Bandura, Albert (1997). Self Efficacy: The Exercise of Control, W.H. Freeman \& Company, New York.

Bauer, Michal, Julie Chytilova and Jonathan Morduch (2010) "Behavioral Foundations of Microcredit," IZA Discussion Paper 4901.

Becker, Gary S. (1962). "Irrational Behavior and Economic Theory” Journal of Political Economy 70 (1): 1-13.

Benhabib, Jess, Alberto Bisin and Andrew Schotter (2010). Present-bias, Quasi-Hyperbolic Discounting, and Fixed Costs. Games and Economic Behavior 69(2), 205-223.

Benson, Todd, "Area-specific fertilizer recommendations for hybrid maize grown by Malawian smallholders: A manual for field assistants." Mimeo, Maize Commodity Team, Chitedze Agricultural Research Station, Malawi, August 1999. Available at: http://www.worldbank.org/html/extdr/fertilizeruse/documentspdf/IsFertApReadings/MAIZE study fert recs_Benson.pdf

Benzion, Yuri, Rapoport, Amnon, and Yagil, Joseph, "Discount Rates Inferred from Decisions: An Experimental Study,” Management Science, 35, 1989, pp. 270-284. 
Beshears, John, James Choi, David Laibson, Brigitte Madrian, and Jung Sakong (2011). "Self Control and Liquidity: How to Design a Commitment Contract." Mimeo, Stanford University.

Brune, Lasse, Xavier Giné, Jessica Goldberg and Dean Yang (2011). Commitments to Save: A Field Experiment in Rural Malawi. Mimeo, University of Michigan.

Bryan, Gharad, Dean Karlan and Scott Nelson (2010). Commitment Devices. Mimeo. Yale University.

Choi, Syngjoo, Ray Fisman, Douglas Gale and Shachar Kariv (2007). Consistency and Heterogeneity of Individual Behavior Under Uncertainty, American Economic Review 97(5), 1921-1938.

Choi, Syngjoo, Shachar Kariv, Wieland Muller, and Dan Silverman (2011). Who Is (More) Rational? Mimeo, University of Michigan.

DellaVigna, Stefano (2009). Psychology and Economics: Evidence from the Field. Journal of Economic Literature, 47(2), 315-372.

Fang, Hanming and Dan Silverman (2009). Time-Inconsistency and Welfare Program Participation: Evidence from the NLSY, International Economic Review, 50(4), 1043-1077

FinScope (2008), "FinScope Malawi 2008”. Available at: http://www.finscope.co.za/documents/2009/Brochure_Malawi08.pdf

Frederick, Shane, George Loewenstein and Ted O’Donoghue (2002). Time Discounting and Time Preference: A Critical Review, Journal of Economic Literature, 40(2), 351-401.

Fuchs, Victor R. (1982). Time Preference and Health: An Exploratory Study, in Victor R. Fuchs, editor, Economic Aspects of Health. University of Chicago Press, Chicago, 93-120.

Fudenberg, Drew and David K. Levine (2006). A Dual Self Model of Impulse Control, American Economic Review 96 (5), 1449-1476.

Economics.

$$
\text { (2010) Timing and Self-Control, mimeo, Harvard University Department of }
$$

Gul, Faruk, and Wolfgang Pesendorfer (2001). Temptation and Self-Control, Econometrica, 69 (6), 1403-1435.

Giné, Xavier, Jessica Goldberg and Dean Yang (forthcoming). Credit Market Consequences of Improved Personal Identification: Field Experimental Evidence from Malawi. American Economic Review.

Halevy, Yoram (2011), “Time Consistency: Stationarity and Time Invariance,” working paper, University of British Columbia.

Harrison, Glenn W., Morten Lau and Elisabet Rustrom (2005). Dynamic Consistency in Denmark: A Longitudinal Field Experiment, Mimeo, Georgia State University.

Hausman, Jerry A. (1979) Individual Discount Rates and the Purchase and Utilization of Energy-using Durables. Bell Journal of Economics 10(1): 33-54.

Kaur, Supreet, Michael Kremer, and Sendhil Mullainathan (2011), "Self-Control at Work," working paper, Harvard University.

Laibson, David (1997). Golden Eggs and Hyperbolic Discounting. Quarterly Journal of Economics, 112(2), pp.443-77.

Laibson, David, Andrea Repetto and Jeremey Tobacman (2007). Estimating Discount Functions with Consumption Choices over the Lifecycle. Mimeo, University of Pennsylvania. Loewenstein, George (1987). Anticipation and the Valuation of Delayed Consumption, Economic Journal 97, pp. 666-684.

Loewenstein, George, and Jon Elster, Choice Over Time (Russell Sage: New York, 1992). 
Meier, Stephan, and Sprenger, Charles (2010). "Stability of Time Preferences.” IZA Discussion Paper No. 4756.

Noor, Jawwad (2011). Time Preference: Experiments and Foundations, mimeo, Boston University.

O’Donoghue, Ted, and Matthew Rabin, (1999) Doing It Now or Later, American Economic Review 89 (March), 103-124.

Ozdenoren, Emre, Stephen Salant, and Dan Silverman, (2009) Willpower and the Optimal Control of Visceral Urges, forthcoming in the Journal of the European Economic Association.

Paserman, Daniele (2008). Job Search and Hyperbolic Discounting: Structural Estimation and Policy Implications. Economic Journal, 118(531), 1418-1452.

Pender, John L. (1996). "Discount rates and credit markets: Theory and evidence from rural India.” Journal of Development Economics 50(2), 257-296.

Schaner, Simone, "Intrahousehold Preference Heterogeneity, Commitment, and Strategic Savings: Theory and Evidence from Kenya,” working paper, Dartmouth College, 2011.

Strotz, Robert H. (1956). Myopia and Inconsistency in Dynamic Utility Maximization, Review of Economic Studies 23, 165-180.

Tanaka, Tomomi, Colin Camerer and Quang Nguyen (2010). Risk and Time Preferences: Experimental and Household Survey Data from Vietnam. American Economic Review 100(1) $557-71$.

Thaler, Richard. H., "Some Empirical Evidence on Dynamic Inconsistency," Economics Letters, 8, 1981, pp. 201-207.

Thaler, Richard T., (1991). Some Empirical Evidence on Dynamic Inconsistency, in Richard H. Thaler, ed.. Quasi Rational Economics. New York: Russell Sage Foundation, 127-33. Warner, John T. and Saul Pleeter (2001). The Personal Discount Rate: Evidence from Military Downsizing. American Economic Review 91(1): 33-53.

World Bank (2006). Malawi Poverty and Vulnerability Assessment. Washington, DC. 
Table 1: Summary Statistics

\begin{tabular}{|c|c|c|c|c|c|c|c|c|}
\hline Variable & $\mathbf{N}$ & Mean & Std. Dev & Min & 10th pctile & 50th pctile & 90th pctile & Max \\
\hline \multicolumn{9}{|l|}{ Panel A: Baseline sample (stage 1) } \\
\hline Change in Allocation to Sooner between Periods Averaged Across All Interest Rates ( & 2142 & 15.69561 & 302.6607 & -2000 & -280 & 0 & 340 & 2000 \\
\hline Fraction Present Biased, All Interest Rates & 2142 & 0.2858077 & 0.2710615 & 0 & 0 & 0.2 & 0.6 & 1 \\
\hline Fraction Present Biased, Non-Implemented Interest Rates & 2142 & 0.284197 & 0.2844093 & 0 & 0 & 0.25 & 0.75 & 1 \\
\hline Fraction of Decisions Consistent with Law of Demand & 2142 & 0.8087652 & 0.1785346 & 0.125 & 0.5 & 0.875 & 1 & 1 \\
\hline Fraction of All Tokens Allocated to "Sooner" & 2142 & 0.3696156 & 0.1900493 & 0 & 0.1 & 0.389 & 0.578 & \\
\hline Implemented Interest Rate & 2142 & 0.6230159 & 0.327678 & 0.1 & 0.1 & 0.75 & 1 & 1 \\
\hline \multicolumn{9}{|l|}{ Demographics } \\
\hline Male & 2142 & 0.4995331 & 0.5001165 & 0 & 0 & 0 & 1 & 1 \\
\hline Respondent's Own Age & 2142 & 46.47059 & 14.0189 & 18 & 28 & 46 & 65 & 95 \\
\hline Age 35 or under & 2142 & 0.2432306 & 0.4291334 & 0 & 0 & 0 & 1 & 1 \\
\hline $36-56$ years old & 2142 & 0.5060691 & 0.5000799 & 0 & 0 & 1 & 1 & 1 \\
\hline Respondent's Spouse's Age & 2142 & 46.47806 & 14.04391 & 18 & 28 & 46 & 65 & 95 \\
\hline Years of Schooling & 2142 & 4.474323 & 4.196598 & 0 & 0 & 4 & 8 & 77 \\
\hline Some Primary School & 2142 & 0.6092437 & 0.4880338 & 0 & 0 & 1 & 1 & 1 \\
\hline Primary School & 2142 & 0.1507937 & 0.3579312 & 0 & 0 & 0 & 1 & 1 \\
\hline More than Primary School & 2142 & 0.0723623 & 0.2591473 & 0 & 0 & 0 & 0 & 1 \\
\hline Have Adequate Maize & 2142 & 0.2161531 & 0.411716 & 0 & 0 & 0 & 1 & 1 \\
\hline Number of Relatives in Village & 2142 & 4.636788 & 8.630064 & 0 & 0 & 2 & 10 & 132 \\
\hline Total Number of People in Village & 2142 & 177.0808 & 258.4724 & 0 & 35 & 120 & 320 & 4000 \\
\hline \multicolumn{9}{|l|}{ Aptitude Questions } \\
\hline Words Recalled - First Time & 2142 & 4.810924 & 1.314317 & 0 & 3 & 5 & 6 & 10 \\
\hline Number Correct on Raven's Matrices & 2142 & 1.527544 & 0.921454 & 0 & 0 & 2 & 3 & 3 \\
\hline Financial Literacy Questions Correct & 2142 & 0.7329599 & 0.9850003 & 0 & 0 & 0 & 2 & 3 \\
\hline \multicolumn{9}{|l|}{ Wealth and Income } \\
\hline Total HH Wealth & 2142 & 11448.53 & 27312.69 & 40 & 1020 & 4446 & 25800 & 695025 \\
\hline HH Total in Bank & 2142 & 447.8565 & 2358.961 & 0 & 0 & 0 & 700 & 54000 \\
\hline HH Total Cash & 2142 & 156.2605 & 1353.264 & 0 & 0 & 0 & 100 & 34000 \\
\hline HH Items & 2142 & 6217.828 & 19736.89 & 0 & 600 & 2346 & 11625 & 588290 \\
\hline HH Animals & 2142 & 4626.581 & 10776.44 & 0 & 0 & 1250 & 12150 & 123600 \\
\hline Expected Income (in period between baseline and revisit) & 2142 & 1758.147 & 6306.995 & 0 & 0 & 50 & 4470 & 137700 \\
\hline \multicolumn{9}{|l|}{ Panel B: Revisit sample (stage 2) } \\
\hline Change in Sooner Allocation upon Revisiting (MK) & 661 & 61.42209 & 595.9793 & -2000 & -600 & 0 & 900 & 2100 \\
\hline Indicator: Change in Sooner Allocation Upon Revisiting is Negative & 661 & 0.3131619 & 0.4641308 & 0 & 0 & 0 & 1 & 1 \\
\hline Indicator: Change in Sooner Allocation Upon Revisiting is Positive & 661 & 0.3403933 & 0.4742003 & 0 & 0 & 0 & 1 & 1 \\
\hline Fraction Present Biased, All Interest Rates & 661 & 0.303177 & 0.2818858 & 0 & 0 & 0.2 & 0.8 & 1 \\
\hline Fraction Present Biased, Non-Implemented Interest Rates & 661 & 0.2991679 & 0.2949115 & 0 & 0 & 0.25 & 0.75 & 1 \\
\hline Fraction of Decisions Consistent with Law of Demand & 661 & 0.8127837 & 0.1725235 & 0.25 & 0.625 & 0.875 & 1 & 1 \\
\hline Fraction of All Tokens Allocated to "Sooner" & 661 & 0.3616238 & 0.1849919 & 0 & 0.111 & 0.378 & 0.567 & \\
\hline Days to First Disbursement at Revisit (Targeted) & 661 & 9.217852 & 4.42353 & 2 & 3 & 10 & 15 & 16 \\
\hline Days to First Disbursement at Revisit (Actual) & 661 & 8.97882 & 4.450009 & 1 & 3 & 9 & 15 & 16 \\
\hline Indicator: Days to First Disbursement (Targeted) is 6 days or less & 661 & 0.3252648 & 0.4688285 & 0 & 0 & 0 & 1 & 1 \\
\hline Implemented Interest Rate & 661 & 0.5811649 & 0.3206835 & 0.1 & 0.1 & 0.75 & 1 & 1 \\
\hline \multicolumn{9}{|l|}{ Shocks } \\
\hline Death in Family & 661 & 0.0226929 & 0.1490353 & 0 & 0 & 0 & 0 & 1 \\
\hline Shock to Expected HH Income & 661 & 114.2061 & 714.5865 & -2985 & -90 & 0 & 350 & 13735 \\
\hline Spouse minus own allocation to sooner (MK) & 661 & 712.2542 & 488.8929 & 0 & 0 & 700 & 1400 & 2000 \\
\hline
\end{tabular}

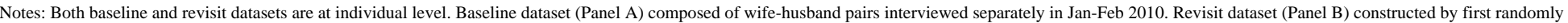

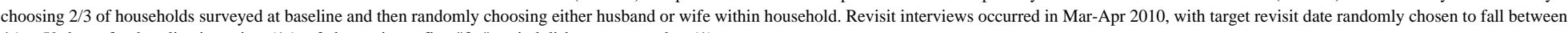
46 to 59 days after baseline interview (16 to 2 days prior to first "far" period disbursement at day 61). 
Table 2: Number (of 8) Positive Changes in Later Allocation with Increase in r

\begin{tabular}{ccc}
\hline Number of Consistent Pairs & $\begin{array}{c}\text { Real Data } \\
(1)\end{array}$ & $\begin{array}{c}\text { Simulated } \\
\text { Data } \\
(2)\end{array}$ \\
\hline 0 & $0.00 \%$ & $0.00 \%$ \\
1 & $0.28 \%$ & $0.04 \%$ \\
2 & $0.61 \%$ & $1.56 \%$ \\
3 & $1.96 \%$ & $12.08 \%$ \\
4 & $7.38 \%$ & $33.92 \%$ \\
5 & $14.05 \%$ & $35.49 \%$ \\
6 & $21.48 \%$ & $14.77 \%$ \\
7 & $22.97 \%$ & $2.05 \%$ \\
8 & $31.28 \%$ & $0.09 \%$ \\
\hline
\end{tabular}

Notes: Table presents share of individuals whose allocations in 8 pairs of choices (with adjacent interest rates) are consistent with law of demand. Data in column (1) are from baseline sample (for details, see Table 1). Data from columns (2) come from simulations described in Appendix B. 
Table 3: Allocations to Later, in Malawi Kwacha, by Time Frame and Rate of Return

\begin{tabular}{|c|c|c|c|c|c|c|c|c|}
\hline & Mean & Std. Dev & 10th & 25th & $\frac{\text { centiles }}{50 \text { th }}$ & 75th & 90th & $\begin{array}{c}\text { Percent at } \\
\text { a corner }\end{array}$ \\
\hline \multicolumn{9}{|l|}{ Near period } \\
\hline $\mathrm{t}+30$ at $\mathrm{r}=10 \%$ & 1295.9 & 524.8 & 660 & 1100 & 1320 & 1650 & 2090 & $13 \%$ \\
\hline $\mathrm{t}+30$ at $\mathrm{r}=25 \%$ & 1535.8 & 602.1 & 750 & 1250 & 1500 & 1875 & 2500 & $14 \%$ \\
\hline$t+30$ at $r=50 \%$ & 1930.5 & 734.0 & 1050 & 1500 & 1950 & 2550 & 3000 & $16 \%$ \\
\hline $\mathrm{t}+30$ at $\mathrm{r}=75 \%$ & 2256.8 & 885.1 & 1050 & 1750 & 2275 & 2975 & 3500 & $17 \%$ \\
\hline $\mathrm{t}+30$ at $\mathrm{r}=100 \%$ & 2713.7 & 1045.4 & 1200 & 2000 & 2800 & 3600 & 4000 & $22 \%$ \\
\hline \multicolumn{9}{|l|}{ Far period } \\
\hline $\mathrm{t}+90$ at $\mathrm{r}=10 \%$ & 1306.7 & 518.7 & 660 & 1100 & 1320 & 1650 & 2090 & $12 \%$ \\
\hline $\mathrm{t}+90$ at $\mathrm{r}=25 \%$ & 1565.4 & 590.0 & 875 & 1250 & 1500 & 2000 & 2500 & $14 \%$ \\
\hline $\mathrm{t}+90$ at $\mathrm{r}=50 \%$ & 1922.9 & 733.2 & 900 & 1500 & 1950 & 2400 & 3000 & $16 \%$ \\
\hline $\mathrm{t}+90$ at $\mathrm{r}=75 \%$ & 2306.5 & 872.0 & 1225 & 1750 & 2275 & 2975 & 3500 & $18 \%$ \\
\hline $\mathrm{t}+90$ at $\mathrm{r}=100 \%$ & 2757.1 & 1030.8 & 1400 & 2000 & 2800 & 3800 & 4000 & $23 \%$ \\
\hline
\end{tabular}

Notes: Data are from baseline sample (for details, see Table 1). Table presents allocations to "later" date (either $t=30$ or $t=90$ ) for each of 10 choices presented to respondents. Baseline interview is at $t=0$. First set of 5 choices is in "near" period, when allocations are between $\mathrm{t}=1$ and $\mathrm{t}=31$. 2 nd set of 5 choices is in "far" period, when allocations are between $\mathrm{t}=61$ and $\mathrm{t}=91$. Rates of return to waiting until "later" date (interest rates) take on values of $10 \%, 25 \%, 50 \%, 75 \%$, and $100 \%$. Allocations between sooner and later date must be made in 100MK increments, out of total budget of 2000MK. 


\section{Table 4: Determinants of Change in $\ln (c)$ From Sooner to Later}

Ordinary least-squares estimates

Dependent variable: Change in $\ln (\mathrm{c})$ from sooner to later

Interest rate (r)

Male

Age 35 or under

36-56 yrs old

Some primary school

Primary school

More than primary school

Have adequate maize

$\log$ (Baseline wealth)

Words recalled

Raven's Tests Correct

Financial Literacy Questions Correct

Number of relatives in the village

Constant

$\mathrm{N}$

Adjusted R-squared delay of 1 vs. 31 days

\begin{tabular}{cc} 
delay of 1 vs. 31 days \\
\hline $0.948^{* * *}$ & $0.949 * *$ \\
$(0.029)$ & $(0.029)$ \\
& 0.026 \\
& $(0.040)$ \\
& 0.061 \\
& $(0.056)$ \\
& 0.056 \\
& $(0.044)$ \\
& 0.008 \\
& $0.047)$ \\
& -0.038 \\
& $(0.072)$ \\
& 0.030 \\
& $(0.097)$ \\
& 0.020 \\
& $(0.047)$ \\
& 0.021 \\
& $(0.015)$ \\
& 0.022 \\
& $(0.014)$ \\
-0.027 \\
$(0.020)$ \\
0.020 \\
$(0.026)$ \\
$0.005 *$ \\
$(0.002)$ \\
$0.224 * *$ \\
$(0.084)$ \\
\\
\\
\end{tabular}

8937

0.09
8937

0.09 delay of 61 vs. 91 days

\begin{tabular}{|c|c|}
\hline $0.935^{* * *}$ & $0.937^{* * *}$ \\
\hline \multirow[t]{25}{*}{$(0.029)$} & (0.029) \\
\hline & 0.024 \\
\hline & $(0.042)$ \\
\hline & 0.061 \\
\hline & $(0.058)$ \\
\hline & 0.041 \\
\hline & $(0.047)$ \\
\hline & -0.012 \\
\hline & $(0.050)$ \\
\hline & -0.087 \\
\hline & $(0.072)$ \\
\hline & -0.010 \\
\hline & $(0.089)$ \\
\hline & 0.046 \\
\hline & $(0.046)$ \\
\hline & $0.033^{* *}$ \\
\hline & $(0.015)$ \\
\hline & 0.022 \\
\hline & $(0.015)$ \\
\hline & $-0.039 *$ \\
\hline & $(0.021)$ \\
\hline & 0.032 \\
\hline & $(0.025)$ \\
\hline & $0.007^{* *}$ \\
\hline & $(0.002)$ \\
\hline $0.414 * * *$ & $0.279 * *$ \\
\hline$(0.030)$ & $(0.089)$ \\
\hline 8931 & 8931 \\
\hline 0.08 & 0.09 \\
\hline
\end{tabular}




\section{Table 5: Determinants of Fraction Consistent or Fraction Present-biased}

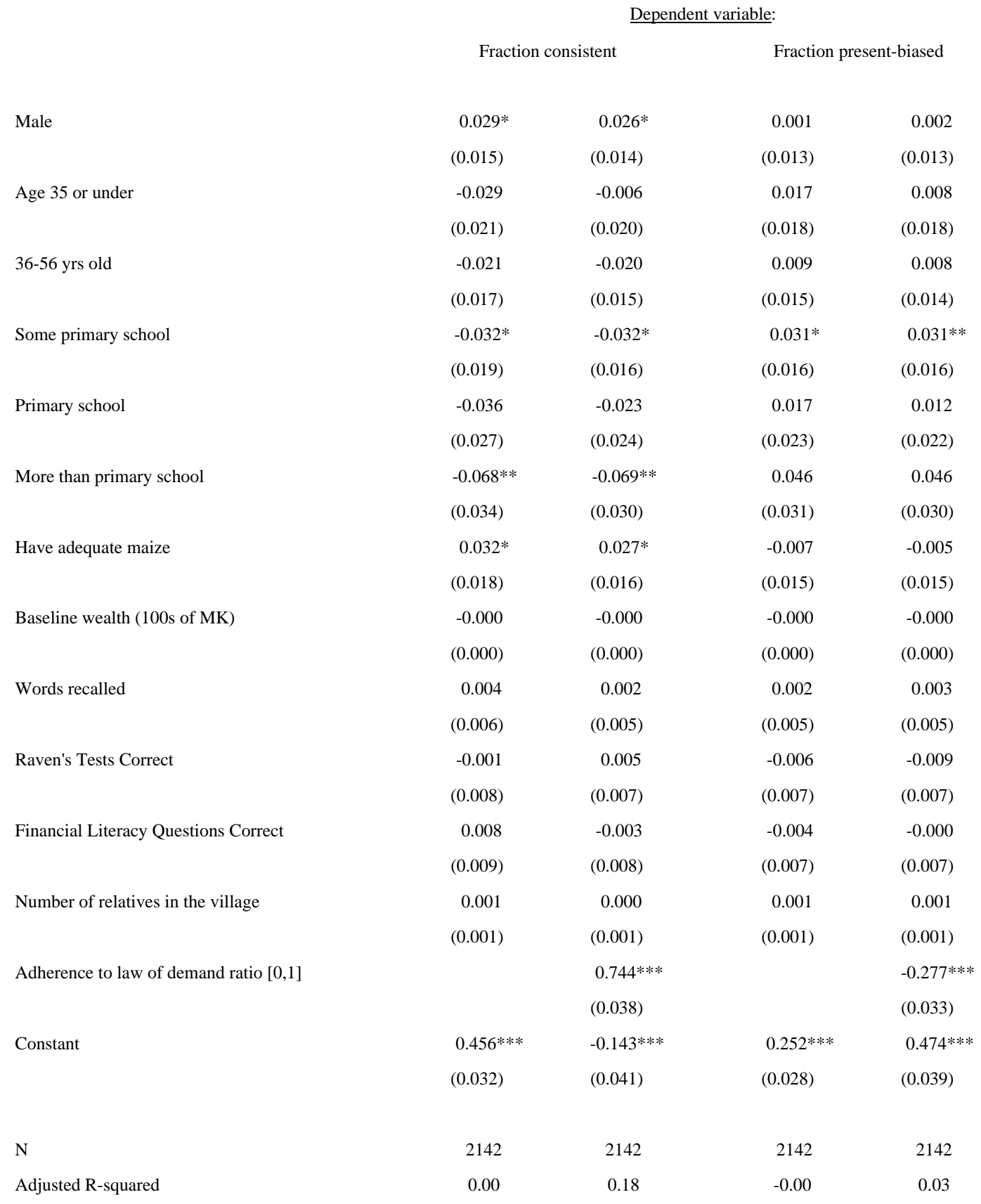

Note: Dependent variable in columns 1 and 2 is the fraction of the five choices pairs that were dynamically consistent. Dependent variable in columns 3 and 4 is the fraction of choice pairs that exhibited present bias. Unit of observation is individuals included in the baseline sample. All allocations made in Jan-Feb 2010. 
Table 6: Determinants of revisions toward sooner

Ordinary least-squares regressions

Dependent variable: Change in sooner allocation upon revisiting (MK)

(1)

Preferences under commitment

Fraction Present Biased, Non-Implemented Interest Rates

Fraction "Future Biased", Non-Implemented Interest Rates

Fraction of all tokens allocated to "sooner"

Indicator: days to first disbursement (targeted) $<=6$

Financial sophistication

Fraction of Decisions Consistent with Law of Demand

Words recalled

Raven's Tests Correct

Financial Literacy Questions Correct

Shocks

Death in the family (indic.)

Shortfall in expected hh income (MK)

Social pressure

Spouse minus own allocation to sooner (MK)

Number of relatives in the village

Rate of return to waiting

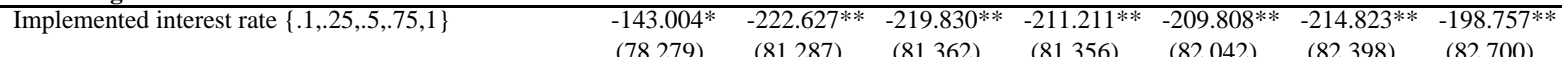

$\begin{array}{llllll}(78.279) & (81.287) & (81.362) & (81.356) & (82.042) & (82.398)\end{array}$

Baseline characteristics

\begin{tabular}{|c|c|c|c|c|c|c|c|}
\hline Male & $\begin{array}{l}125.169 * * \\
(49.851)\end{array}$ & $\begin{array}{l}101.800^{* *} \\
(49.488)\end{array}$ & $\begin{array}{l}\text { 103.931** } \\
\text { (51.698) }\end{array}$ & $\begin{array}{l}106.341^{* *} \\
(51.561)\end{array}$ & $\begin{array}{l}101.039 * \\
(53.196)\end{array}$ & $\begin{array}{r}55.018 \\
(61.402)\end{array}$ & $\begin{array}{r}65.022 \\
(61.254)\end{array}$ \\
\hline \multirow[t]{2}{*}{ Age 35 or under } & $198.798 * *$ & $181.737^{* *}$ & $177.816^{* *}$ & $175.745^{* *}$ & $175.145^{* *}$ & $274.587 * *$ & $284.957 * *$ \\
\hline & $(71.742)$ & (71.257) & (71.515) & (71.968) & $(72.490)$ & (110.102) & (109.770) \\
\hline \multirow[t]{2}{*}{$36-56$ yrs old } & $117.670^{* *}$ & $111.136^{* *}$ & $114.283^{* *}$ & $117.301^{* *}$ & $115.631 * *$ & $176.259 * *$ & $175.243^{* *}$ \\
\hline & $(54.887)$ & $(54.764)$ & $(54.258)$ & (54.399) & $(56.237)$ & $(64.895)$ & $(64.866)$ \\
\hline \multirow[t]{2}{*}{ Some primary school } & -66.952 & -75.753 & -70.217 & -68.240 & -69.187 & -28.764 & -17.569 \\
\hline & $(70.212)$ & (68.797) & (71.864) & $(70.170)$ & (70.687) & $(72.040)$ & (72.289) \\
\hline \multirow[t]{2}{*}{ Primary school } & $-159.166^{*}$ & $-160.924 *$ & $-155.726^{*}$ & $-163.630^{*}$ & $-165.420 *$ & -123.579 & -114.183 \\
\hline & $(85.954)$ & $(84.696)$ & $(91.235)$ & $(90.493)$ & $(90.649)$ & $(92.800)$ & $(92.611)$ \\
\hline \multirow[t]{2}{*}{ More than primary school } & $-215.094 * *$ & $-217.068^{* *}$ & $-202.690 *$ & $-205.617^{*}$ & $-206.031 *$ & -132.108 & -127.624 \\
\hline & $(105.964)$ & (104.938) & (117.169) & (115.693) & (115.753) & $(119.426)$ & $(120.370)$ \\
\hline \multirow[t]{2}{*}{ Have adequate maize } & 35.744 & 25.040 & 28.679 & 25.645 & 23.730 & 6.327 & 1.060 \\
\hline & $(56.325)$ & $(55.110)$ & $(55.840)$ & (56.737) & $(57.724)$ & (57.737) & (57.919) \\
\hline \multirow[t]{2}{*}{ Total HH Wealth } & -0.122 & -0.125 & -0.126 & -0.130 & -0.128 & -0.124 & -0.123 \\
\hline & $(0.089)$ & $(0.086)$ & $(0.085)$ & $(0.084)$ & $(0.085)$ & $(0.089)$ & $(0.091)$ \\
\hline Spousal characteristics & - & - & - & - & - & $\mathrm{Y}$ & $\mathrm{Y}$ \\
\hline R-squared (adj.) & 0.02 & 0.05 & 0.04 & 0.04 & 0.04 & 0.05 & 0.04 \\
\hline $\mathrm{N}$ & 661 & 661 & 661 & 661 & 661 & 661 & 661 \\
\hline P-value for test that financi & & & 0.87 & 0.88 & 0.88 & 0.90 & 0.85 \\
\hline
\end{tabular}

Significance levels: * $10 \%, * * 5 \%, * * * 1 \%$. Robust standard errors in parentheses.

Notes: Unit of observation is individual included in revisit sample. Spousal characteristics controls are: fraction present biased for all choices, indicators for age category, indicators for education category, word recall, ravens score, financial literacy score, and fraction of choices adhering to law of demand. 


\section{Table 7: Relative magnitudes of estimated empirical relationships}

Effect on revisions to

Independent variable

Hypothetical shift

sooner (MK)

Implemented rate of return $\{.1, .25, .5, .75,1\}$

50 percentage point reduction

107.41

Fraction Present Biased, Non-Implemented Interest Rates

0.28 increase (1 std. dev.)

41.88

Days to first disbursement $<=6$ (indic.)

From 0 to 1

124.57

Note: Calculations use coefficients in Table 6, column 6 . 
Table 8: Determinants of inclusion in revisit sample

Ordinary least-squares regressions

Dependent variable: Indicator for inclusion in revisit sample

Preferences under commitment

\begin{tabular}{lc}
\hline Fraction Present Biased, Non-Implemented Interest Rates & 0.002 \\
Fraction of all tokens allocated to "sooner" & $(0.035)$ \\
& -0.031 \\
Indicator: days to first disbursement (targeted) $<=6$ & $(0.097)$ \\
& $-0.108^{* * *}$ \\
Fraction of Decisions Consistent with Law of Demand & $(0.025)$ \\
Words recalled & 0.001 \\
& $(0.076)$ \\
Raven's Tests Correct & $-0.015^{*}$ \\
Financial Literacy Questions Correct & $(0.008)$ \\
& 0.019 \\
& $(0.013)$ \\
& 0.005 \\
\end{tabular}

Social pressure

$\begin{array}{lr}\text { Spouse minus own allocation to sooner (MK) } & -0.000 \\ \text { Number of relatives in the village } & (0.000) \\ & 0.001 \\ (0.002)\end{array}$

Rate of return to waiting

Implemented interest rate $\{.1, .25, .5, .75,1\}$

(0.036)

Baseline characteristics

$\begin{array}{lc}\text { Male } & 0.036 \\ \text { Age } 35 \text { or under } & (0.030) \\ \text { 36-56 yrs old } & 0.080^{*} \\ \text { Some primary school } & (0.044) \\ & -0.037 \\ \text { Primary school } & (0.031) \\ & -0.034 \\ \text { More than primary school } & (0.029) \\ & -0.055 \\ \text { Have adequate maize } & (0.045) \\ \text { Total HH Wealth } & -0.056 \\ & (0.045) \\ & 0.007 \\ & (0.027) \\ & -0.000 * * * \\ \end{array}$

Controls for:

$\begin{array}{ll}\text { Spousal characteristics } & \text { Y }\end{array}$

R-squared (adj.) $\quad 0.05$

$\mathrm{N}$

Significance levels: * 10\%, ** 5\%, *** 1\%. Robust standard errors in parentheses.

Notes: Unit of observation is individuals targeted for inclusion in revisit sample. Dependent variable has mean of 0.916. Right-hand-side variables are identical to column 6, Table 6, except for omission of shock variables ("death in family" and "shortfall in expected household income"), because shock variables are not available for attriters. See Table 6 for other notes. 
Table 9: Differential effects by gender

Ordinary least-squares regressions

Dependent variable: Change in sooner allocation upon revisiting (MK)

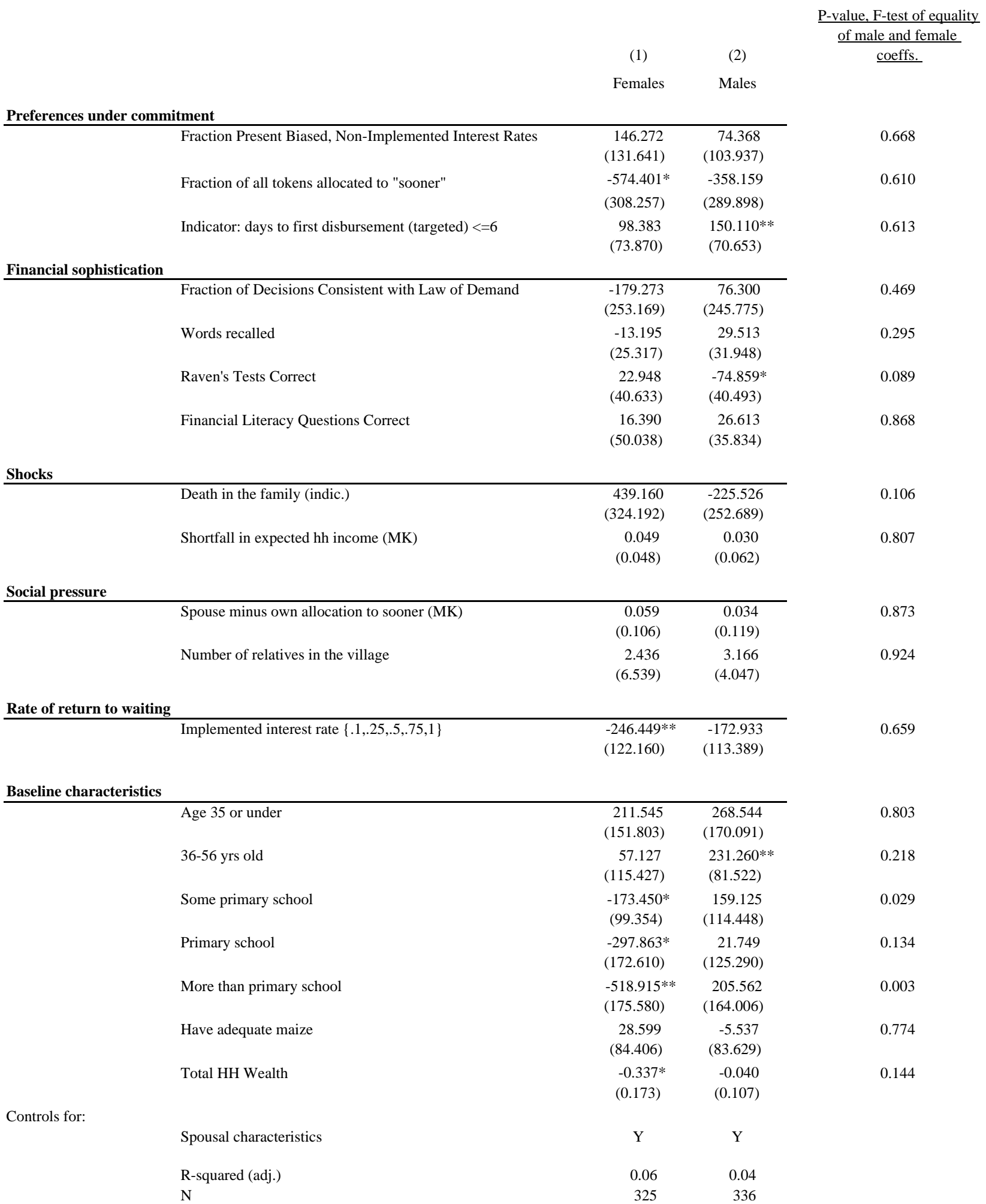

Significance levels: * $10 \%, * * 5 \%, * * * 1 \%$. Robust standard errors in parentheses.

Notes: Unit of observation is individual included in revisit sample. Column 1 restricts to females in revisit sample. Column 2 restricts to males in revisit sample. See Table 6 for other notes. 
Appendix Table 1: Tests of baseline balance with respect to randomized independent variables

Ordinary least-squares regressions

Dependent variable:

$\begin{array}{ccc}\text { Fraction } & \text { Fraction of } & \text { Fraction of } \\ \text { Present } & \text { all tokens } & \text { Decisions } \\ \text { Biased, Non- } & \text { allocated to } & \text { Consistent } \\ \text { Implemented } & \text { "sooner" } & \begin{array}{c}\text { with Law of } \\ \text { Interest Rates }\end{array} \\ & & \text { Demand }\end{array}$

Panel A

Indicator: days to first disbursement (targeted) $<=6$

R-squared

$\mathrm{N}$

Panel B

Implemented interest rate $\{.1,25, .5, .75,1\}$

$-0.033$

(0.021)

$0.034^{*}$

0.0432

0

R-squared

$-0.035 * *$

661

(0.015)

0.0007

661

0.0040
Words Recalled Correct

Literacy
Questions

Correct

$\begin{array}{cc}\begin{array}{cc}\text { Spouse minus } \\ \text { own }\end{array} & \begin{array}{c}\text { Number of } \\ \text { Relatives in }\end{array} \\ \text { allocation to } & \text { the Village } \\ \text { sooner (MK) } & \end{array}$

Male sooner (MK)

$\mathrm{N}$

$(0.164) \quad(0.109)$

0.026

(0.117)

0.000

661

0.062
$(0.074)$

0.0010

661

$-0.074$

$(0.080)$

$80.415^{*}$

(41.852)

$-0.381$

(0.573)

0.0006

661

661

66

(0.041)

0.0039

661

$-0.030$

(1.145)

0.0000

661

-0.144
$(0.263)$

0.002

(0.036)

0.000

0.0000

661

$(13.074)$

$0.448 * * * \quad 0.075$

0.0113

661

$\begin{array}{ccc}0.012 & 129.492^{* *} & -1.205 \\ (0.116) & (61.027) & (0.887) \\ & & \\ 0.0000 & 0.0070 & 0.0027 \\ 661 & 661 & 661\end{array}$

-0.083
$(0.061)$
0.0028
661

-0.996
$(1.620)$
0.0006
661

0.558

(0.381)

$-0.058$

(0.052)

$\begin{array}{cccc}0.0007 & 0.0000 & 0.0070 & 0.0027 \\ 661 & 661 & 661 & 661\end{array}$

661

661

0.001

661

0.0004

Significance levels: $* 10 \%, * * 5 \%, * * * 1 \%$. Robust standard errors in parentheses.

Notes: Unit of observation is individual included in revisit sample. In Panel A, each column presents results from regression of give

but independent variable is interest rate on randomly-chosen choice. Constant term included in each regression but not reported. 
Appendix Table 2: Determinants of revisions toward sooner (using all first-stage choices in measure of present bias)

Ordinary least-squares regressions

Dependent variable: Change in sooner allocation upon revisiting (MK)

$(1)$

(3)

(4)

(5)

(6)

(7)

\section{Preferences under commitment}

Fraction Present Biased, All Interest Rates

$\begin{array}{lllll}228.165^{* *} & 223.450^{* *} & 224.583^{* *} & 222.907^{* *} & 231.639^{* *} \\ (83.387) & (83.721) & (83.845) & (84.961) & (84.062)\end{array}$

Fraction "Future Biased", All Interest Rates

$\begin{array}{r}-28.740 \\ \hline\end{array}$

Fraction of all tokens allocated to "sooner"

Indicator: days to first disbursement (targeted) $<=6$

$\begin{array}{lllll}-611.757 * * * & -638.390 * * * & -621.955 * * * & -636.684 * * & -642.477 * *\end{array}$

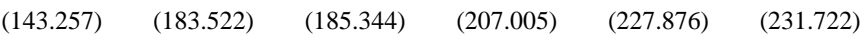

$\begin{array}{llllll}106.374 * * & 107.778^{* *} & 110.152^{* *} & 110.601^{* *} & 122.925^{* *} & 121.264^{* *}\end{array}$

Financial sophistication

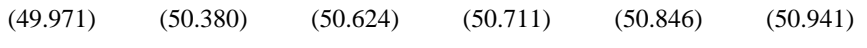

Fraction of Decisions Consistent with Law of Demand

Words recalled

Raven's Tests Correct

Financial Literacy Questions Correct

$\begin{array}{rrrrr}-65.595 & -48.868 & -48.832 & -62.645 & -129.462 \\ (173.256) & (173.867) & (174.149) & (173.680) & (176.896) \\ -3.836 & -3.255 & -3.081 & -1.943 & -0.056 \\ (18.868) & (18.783) & (18.895) & (18.944) & (19.120) \\ -28.042 & -28.494 & -28.897 & -21.144 & -23.867 \\ (28.240) & (28.439) & (28.361) & (28.753) & (29.044) \\ 15.036 & 13.641 & 13.422 & 22.704 & 24.433 \\ (28.200) & (28.032) & (28.231) & (28.347) & (28.399)\end{array}$

Shocks

Death in the family (indic.)

Shortfall in expected hh income (MK)

$\begin{array}{cccc}63.533 & 64.467 & 54.700 & 59.404 \\ (201.166) & (201.237) & (200.063) & (202.298) \\ 0.048 & 0.048 & 0.045 & 0.044 \\ (0.042) & (0.042) & (0.039) & (0.038)\end{array}$

Social pressure

Spouse minus own allocation to sooner (MK)

Number of relatives in the village

$\begin{array}{rrr}-0.008 & 0.016 & -0.007 \\ (0.063) & (0.081) & (0.080) \\ 0.641 & 1.350 & 1.685 \\ (3.534) & (3.411) & (3.370)\end{array}$

Rate of return to waiting

\begin{tabular}{|c|c|c|c|c|}
\hline Implemented interest rate $\{.1, .25, .5, .75,1\}$ & $\begin{array}{l}-143.004^{*} \\
(78.279)\end{array}$ & $\begin{array}{l}-221.012^{* *} \\
(79.852)\end{array}$ & $\begin{array}{l}-218.117 * \\
(79.857)\end{array}$ & $\begin{array}{r}-209.918 * \\
(79.890)\end{array}$ \\
\hline
\end{tabular}

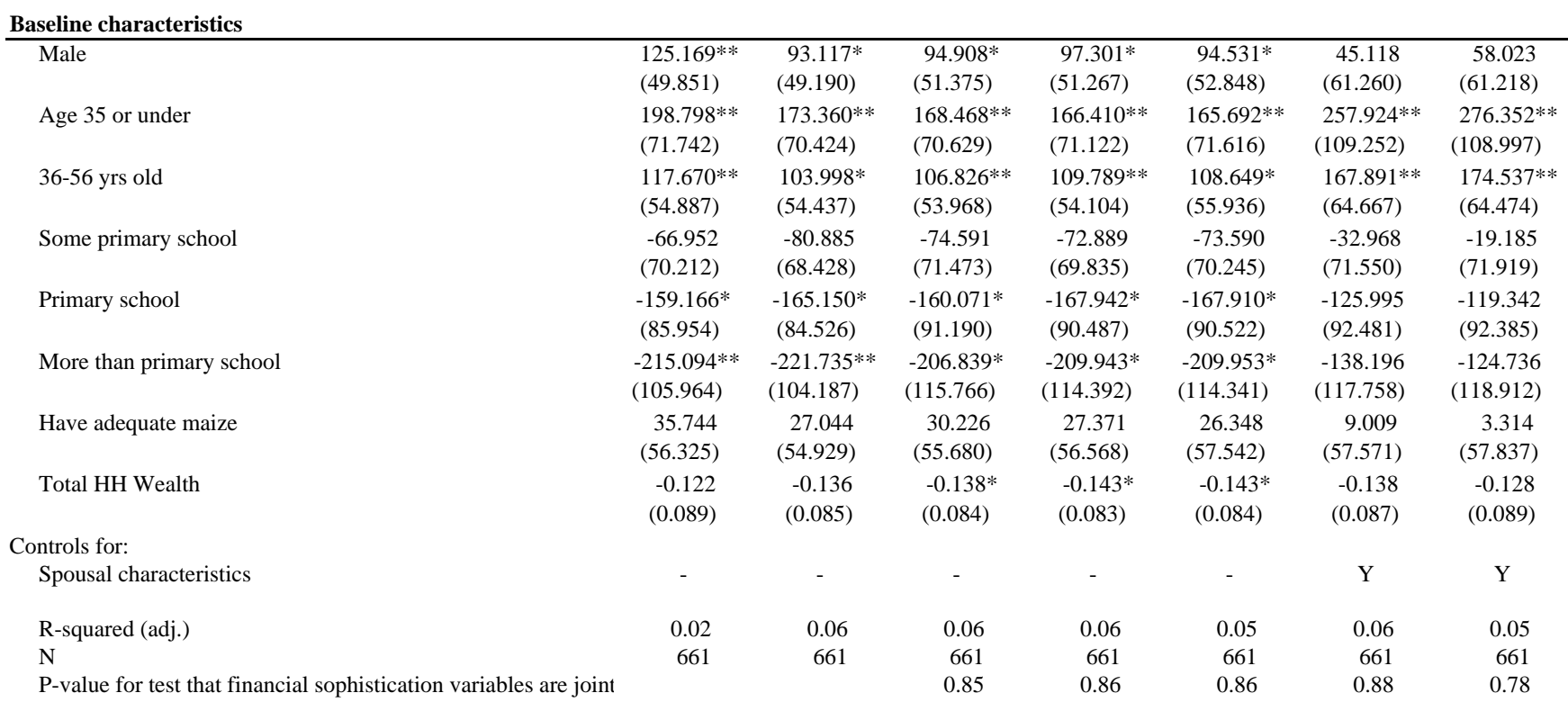

Significance levels: * $10 \%, * * 5 \%, * * * 1 \%$. Robust standard errors in parentheses.

Notes: Unit of observation is individual included in revisit sample. Spousal characteristics controls are: fraction present biased for all choices, indicators for age category, indicators for education category, word recall, ravens score, financial literacy score, and fraction of choices adhering to law of demand. 


\section{Appendix Table 3: Random vs Real choice}

Ordinary least-squares regressions

Dependent variable: Change in sooner allocation upon revisiting (MK)

$\begin{array}{cc}(1) & (2) \\ \text { Real } & \text { Simulated } \\ & \\ \text { 49.559*** } & 705.308 \\ (83.269) & {[467.5,948.9]}\end{array}$

(4)

(6)

(7)

Hyperbolic preferences

Fraction Present Biased [0,1]

Fraction Present Biased, Non-Implemented Interest Rate

$\begin{array}{lc}148.669 * & 0.763 \\ (82.106) & {[-225.6,225.6]}\end{array}$

Fraction Future Biased [0,1]

Fraction Future Biased, Non-Implemented Interest Rate

Fraction of all tokens allocated to "sooner" [0,1]

\section{$-536.245 * * \quad-1997.214$ \\ (225.933) [ [-2734.4, -1218.4]}

Fraction of all tokens allocated to "sooner", non-Implemented Interest Rate

Financial sophistication

Fraction of Decisions Consistent with Law of Demanc

$\begin{array}{cccc}-66.484 & 133.243 & -26.708 & 387.200 \\ (173.956) & {[-313.8,567.6]} & (175.075) & {[-69.7,851.3]}\end{array}$

$-476.630 * * \quad 52.466$

(227.564) [ $\quad$-672.1, 821.8]

$\begin{array}{cc}-36.064 & -707.562 \\ (96.468) & {[-936.4,-475.6]}\end{array}$

81.460

$-2.150$

(90.885) [ [-220.6, 211.8]

$-534.990 * * \quad-1994.620$

(229.755) [ -2738.1, -1210.8]

$-474.870 * * \quad 52.622$

(228.706) $\quad[-678.2,826.9]$

$\begin{array}{llll}-141.406 & 132.721 & -31.727 & 387.245\end{array}$

(176.978) [ - 2738.1, -1210.8] (178.077) [ -69.1, 855.3]

\section{Social pressure}

$\begin{array}{ccc}\text { Spouse minus own allocation to sooner (MK) } & 0.068 & 0.004 \\ & (0.078) & {[-0.28,0.30]}\end{array}$

Spouse minus own allocation to sooner (MK), non-Implemented Interest Rate

$\begin{array}{rc}0.047 & 0.004 \\ (0.081) & {[-0.28,0.28]}\end{array}$

$\begin{array}{cc}0.052 & 0.005 \\ (0.077) & {[-0.28,0.31]}\end{array}$

$0.034 \quad 0.004$

$(0.080) \quad[-0.28,0.29]$

Rate of return to waiting

Implemented interest rate $\{.1, .25, .5, .75,1\}$

$\begin{array}{cc}-211.245^{* * *} & -0.292 \\ (80.386) & {[-162.9,174.5]}\end{array}$

$\begin{array}{lc}-214.823^{* *} & 1.785 \\ (82.398) & {[-170.5,188.3]}\end{array}$

$-196.598 *$

0.232

$-198.757 * *$

1.690

[ 81.303$) \quad-164.3,178.7]$

(82.700) [ $\quad$-169.6, 188.7]

\section{Controls for:}

\section{Spousal characteristics}

$\mathrm{N}$

$\begin{array}{cc}\mathrm{Y} & \mathrm{Y} \\ 661 & 661\end{array}$

\section{Y}

661
Y

661

\section{Y}

661
Y

661
$\mathrm{Y}$

661

Significance levels: * $10 \%, * * 5 \%, * * * 1 \%$. Robust standard errors in parentheses.

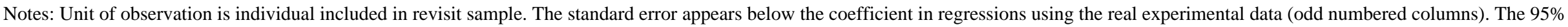

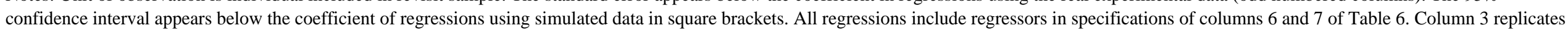
column 6 in Table 6, and column 7 replicates column 7 in Table 6. 
Appendix Table 4: Bounds on bias due to selection into revisit sample Ordinary least-squares regressions

Dependent variable: Change in sooner allocation upon revisiting (MK), with missing values replaced

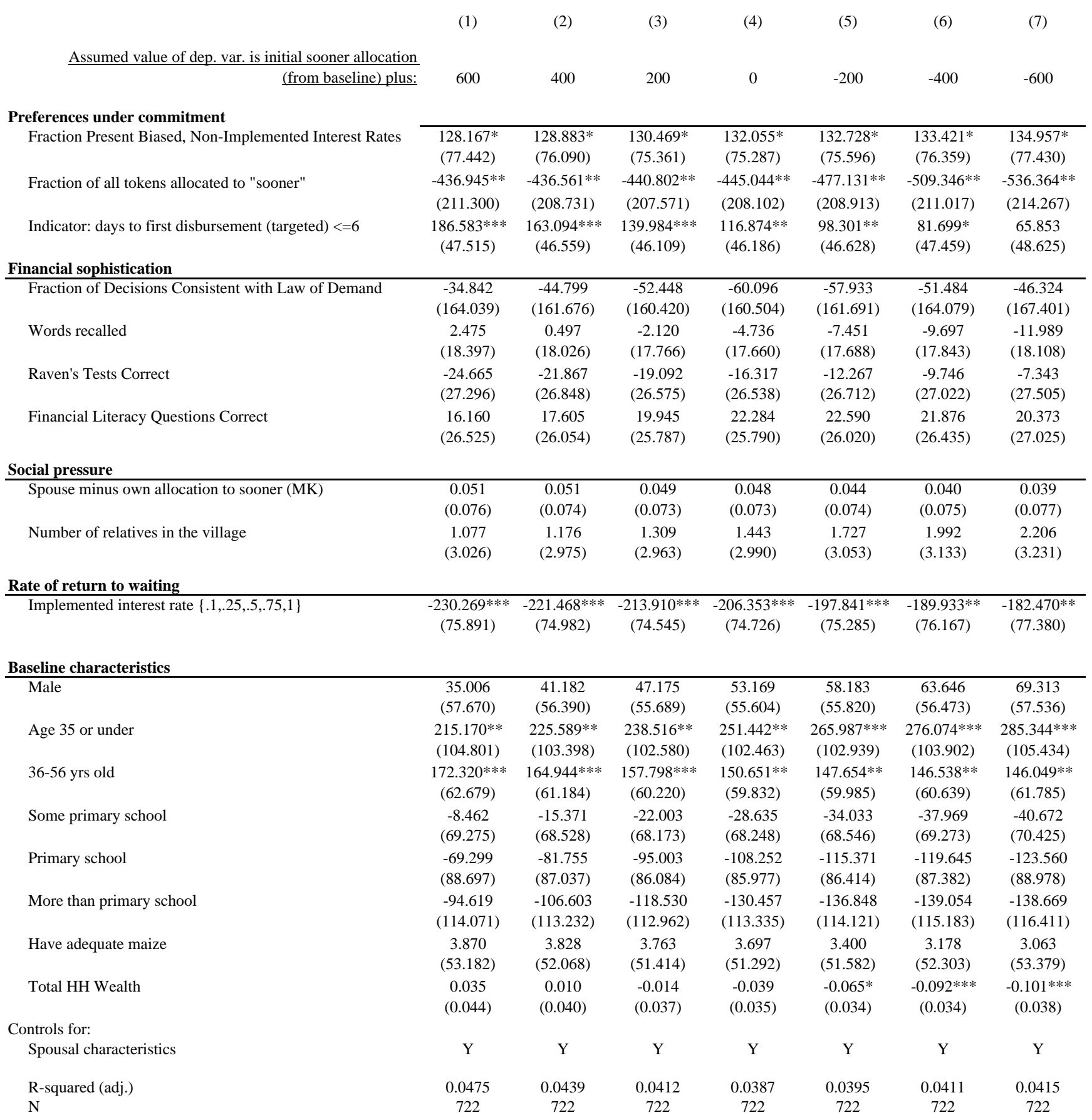

Significance levels: * 10\%, ** 5\%, *** 1\%. Robust standard errors in parentheses.

Notes: Dependent variable constrained to remain within 0 or 2000 range. Right-hand-side variables are identical to column 6, Table 6, except for omission of shock variables ("death in family" and "shortfall in expected household income"), because shock variables are not available for attriters. See Table 6 for other notes. 
Figure 1: Schematic of the Preference Elicitation Method; Example with $r=0.25$

\section{$800 \mathrm{MK}$}

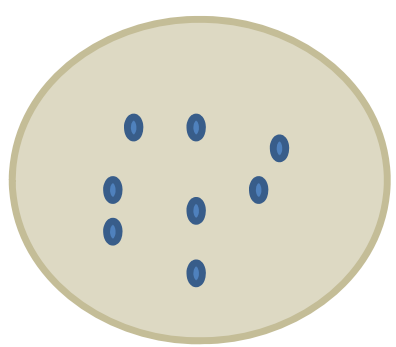

$\operatorname{Dish}(A)$

Allocation to time $t$
1500MK

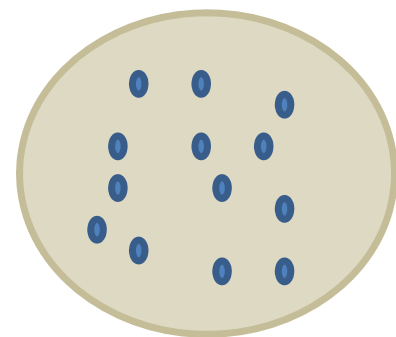

$\operatorname{Dish}(B)$

Allocation to time $t+30$ 
Figure 2: Schematic of the Revising Procedure; Example with $r=0.25$

\section{MK}

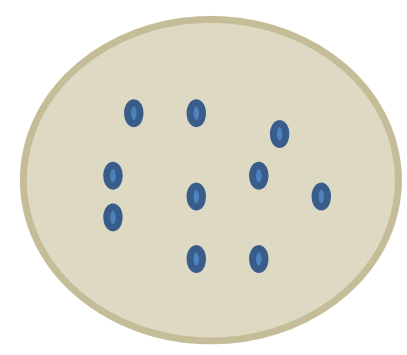

$\operatorname{Dish}\left(A^{\prime}\right)$

$(R e)$ allocation to time $t$

\section{$800 \mathrm{MK}$}

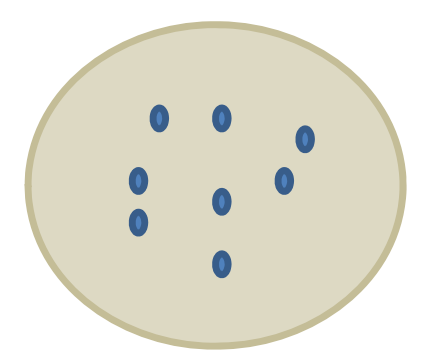

$\operatorname{Dish}(A)$

Original allocation to time $t$

\section{MK}

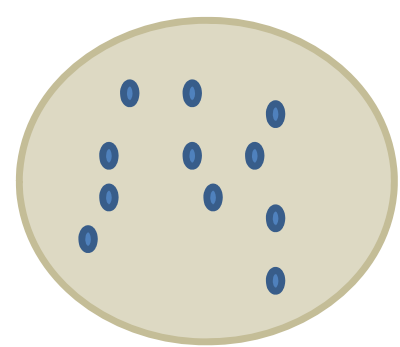

$\operatorname{Dish}\left(B^{\prime}\right)$

(Re)allocation to time $t+30$

\section{MK}

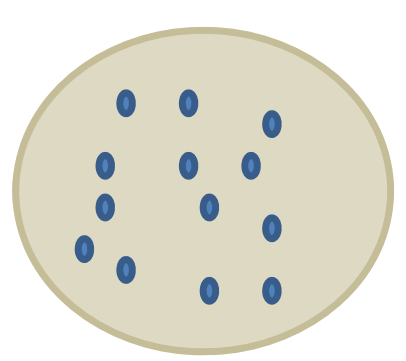

Dish (B)

Bowl with Original allocation to time $t+30$ 


\section{Figure 3: Timeline of Interviews, Choices, and Disbursement of Funds}

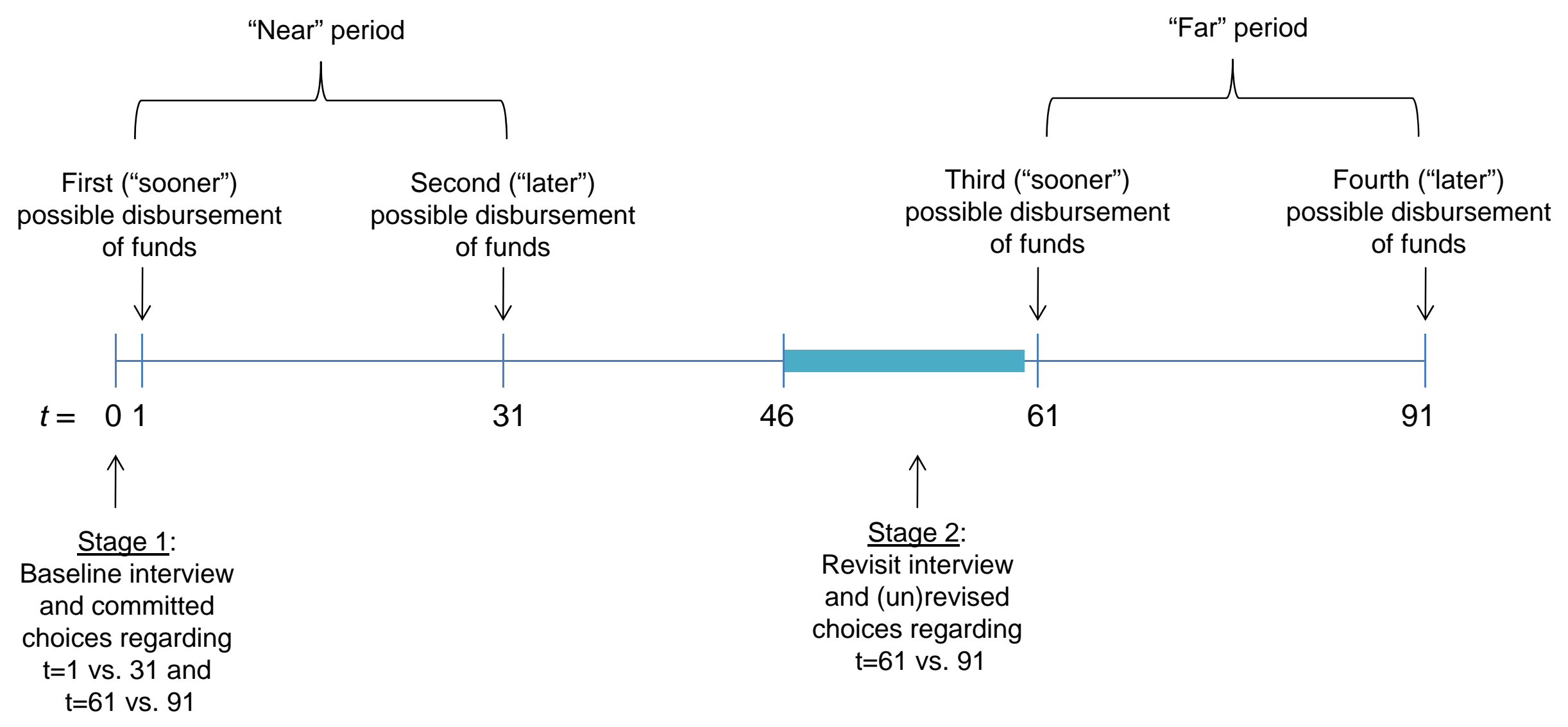




\section{Figure 4: Distribution of Change in Sooner Allocation Upon Revisiting}

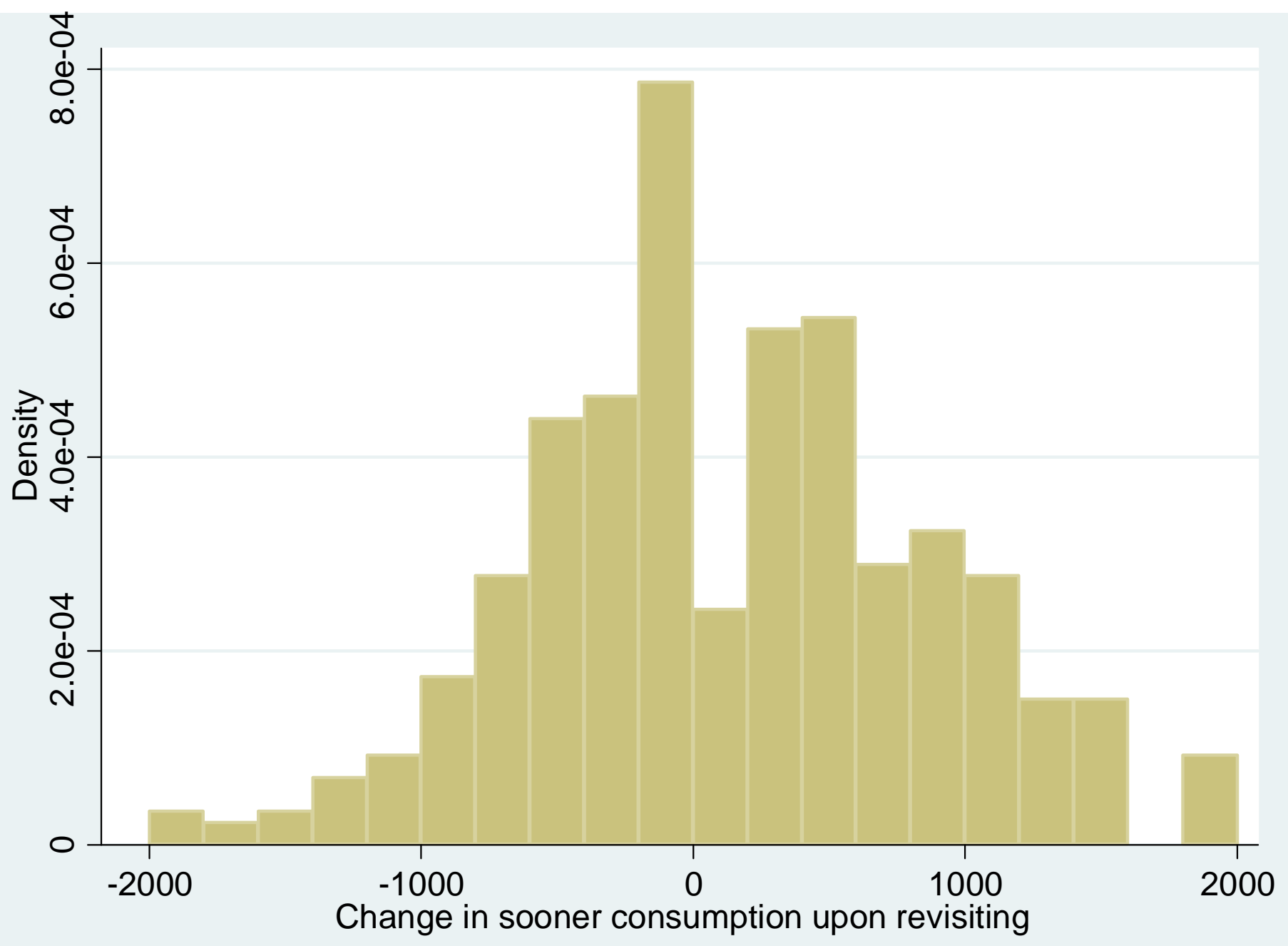

Notes: Observations with no change in allocation excluded from histogram. Initial allocations made in Jan-Feb 2010. Revisions made in Mar-Apr 2010 in a revisit targeted at a randomized 2-16 days prior to date of first disbursement in "far" period. (Date of first disbursement in far period is day $t=61$ from initial visit in Jan-Feb 2010.) 
Figure 5: Impact of targeted days before disbursement on revisions toward sooner

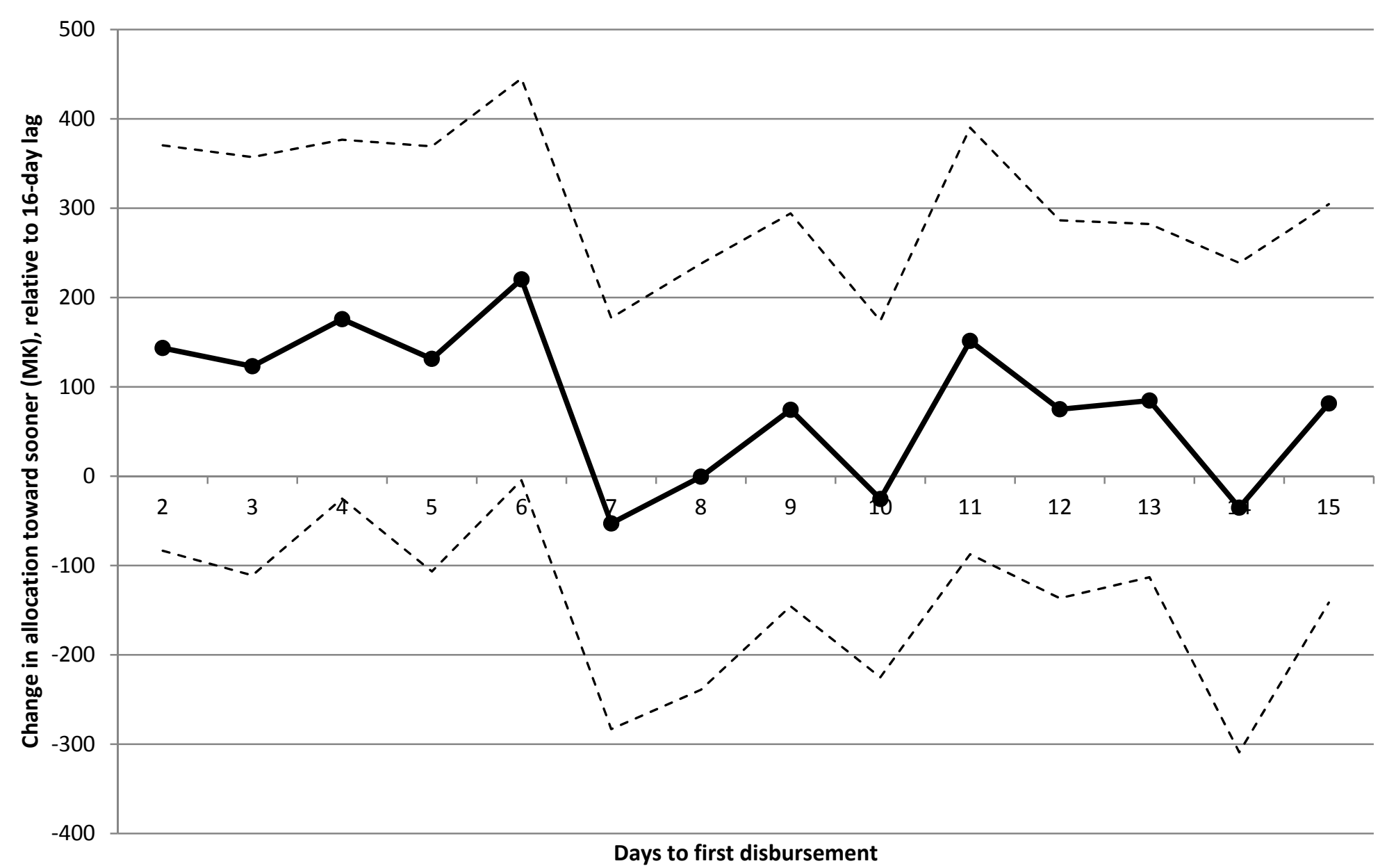

Coefficient - - - - Upper 95\% confidence interval _ - - Lower 95\% confidence interval

Notes: Figure plots coefficient (and 95\% confidence interval) on indicator variables for each separate value of days to first disbursement (omitted category is 16 days to first disbursement). Dependent variable is change in allocation to sooner upon revisiting (in MK). Other right-hand-side variables are as in Table 6, column 6. 